\title{
Relationships Between Ion Channels, Mitochondrial Functions and Inflammation in Human Aging
}

\author{
Marie Strickland ${ }^{1,2 *}$, Besma Yacoubi-Loueslati ${ }^{3}$, Balkiss Bouhaouala-Zahar ${ }^{4,5}$, \\ Sylvia L. F. Pender ${ }^{2,6}$ and Anis Larbi ${ }^{1,7,8,9 *}$
}

${ }^{1}$ Singapore Immunology Network, Agency for Science Technology and Research, Singapore, Singapore, ${ }^{2}$ Clinical and Experimental Sciences, Faculty of Medicine, University of Southampton, Southampton, United Kingdom, ${ }^{3}$ Laboratory of Mycology, Pathologies and Biomarkers, Department of Biology, Faculty of Sciences, University Tunis El Manar, Tunis, Tunisia, ${ }^{4}$ Laboratory of Venoms and Therapeutic Molecules, Institut Pasteur de Tunis, University Tunis El Manar, Tunis, Tunisia, ${ }^{5}$ Medical School of Tunis, University Tunis El Manar, Tunis, Tunisia, ${ }^{6}$ Chinese University of Hong Kong - University of Southampton Joint Lab for Stem Cell and Regenerative Medicine, Hong Kong, China, ${ }^{7}$ Department of Biology, Faculty of Sciences, University Tunis El Manar, Tunis, Tunisia, ${ }^{8}$ Department of Microbiology and Immunology, Yong Loo Lin School of Medicine, National University of Singapore, Singapore, Singapore, ${ }^{9}$ Geriatrics Division, Department of Medicine, Research Center on Aging, University of Sherbrooke, Sherbrooke, QC, Canada

Aging is often associated with a loss of function. We believe aging to be more an adaptation to the various, and often continuous, stressors encountered during life in order to maintain overall functionality of the systems. The maladaptation of a system during aging may increase the susceptibility to diseases. There are basic cellular functions that may influence and/or are influenced by aging. Mitochondrial function is amongst these. Their presence in almost all cell types makes of these valuable targets for interventions to slow down or even reserve signs of aging. In this review, the role of mitochondria and essential physiological regulators of mitochondria and cellular functions, ion channels, will be discussed in the context of human aging. The origins of inflamm-aging, associated with poor clinical outcomes, will be linked to mitochondria and ion channel biology.

Keywords: aging, mitochondria, ion channels, inflammation, cellular senescence

\section{AGING: A PHYSIOLOGICAL ADAPTATION}

\section{Chronological Aging}

The definition of aging has been of great debate between scientists. Many view aging as a disease itself, whilst others describe aging as the inevitable decline of function with time which increases propensity to age-related disease development. Victor Hugo said: "Forty is the old age of youth, fifty is the youth of old age" already suggesting strata to exist within each of the periods of life. In this review, we define aging as individuals in the last stage of their life, often represented in the literature as retirement age (65 years old). The life expectancy in developed countries is longer (83 years in Singapore, 81 years in United Kingdom). Nevertheless, most countries will be approaching a critical demography during this century, including extended life expectancy (75 years in Tunisia), reduced birth rate and reduced workforce (World Health Organization, 2015). While aging of the population is currently seen as a socio-economic burden it is possible to make it an opportunity. The current view is highly influenced by the fact that many of the elderly also display diseases and disabilities (World Health Organization, 2015; Vos et al., 2017). For example, the decline 
of pulmonary, cardiovascular and immune systems has been shown in longitudinal aging studies, alongside physical decline such as sarcopenia and frailty (Ng et al., 2015; Shimokata and Ando, 2017; Huang et al., 2018). These may lead to loss of physical integrity, impaired function and vulnerability to death. Physiological aging can take two forms: (1) the normal decline in function, which occurs in all individuals with age, and (2) the loss of function from one or more diseases encountered with age (Hayflick, 1994). Whilst the first may be seen by many as untreatable, the second form often is treatable due to the great strides we have made in treating and controlling age-related diseases such as diabetes and atherosclerosis. In order to better integrate the elderly population in our societies it is of utmost importance to understand how to increase healthspan. While assistive technologies are necessary to fill the gap, the long-term challenge is to prevent the elderly from physical decline.

\section{Biological Aging}

We view aging as an adaptation to lifelong events, and interventions should support the physiological balance during age-related adaptation, response to acute stress, in order to avoid disease onset. Adapted capacity in most organs has been shown to occur from the third and fourth decades of life (Boss and Seegmiller, 1981; Khan et al., 2017). Chronological age by itself is not a great predictor of aging, healthspan or functional status (Yang and Lee, 2009), with individuals of the same age putting vastly different demands on health care systems and society in general. Whilst the incidence of the top five chronic diseases increases with age, $32 \%$ of the participants aged 85 and over in the 2004 US Health and Retirement study were not diagnosed with these conditions. Additionally, $28 \%$ of those 85 and over reported themselves as in excellent or very good health compared to $48 \%$ of the $51-54$ age bracket (Lowsky et al., 2014). The future of aging research may depend on our ability to stratify elderly populations and predict clinical trajectories of the presymptomatic adult populations. Young individuals of the same chronological age (38 years) have been found to vary in their biological age, measured by the functional decline of multiple organ systems prior to the onset of age-related disease (Belsky et al., 2015). Young individuals with an advanced pace of aging show increased physical and neurological decline compared to their slower aging counterparts between the ages of 26 and 38 (Belsky et al., 2015). This pool with a faster pace of aging could be used to evaluate the effectiveness of anti-aging therapies prior to disease onset.

Methods to assess biological age and the rate of aging are varied. Measurements can range from simple one-off measurements of telomere length to complex measurements of epigenetic ticking rate and algorithms of biomarkers taken over time (Belsky et al., 2018). Whilst agreement between different measures of biological aging is low, the 71-cytosine-phosphateguanine epigenetic clock and biomarker algorithms were recently found to be more reliable than other methods in relation to physiological decline of organs and facial aging (Belsky et al., 2018). Recent focus has been on understanding more about epigenetic markers of aging (Mitnitski, 2018). Methylation within certain $\mathrm{CpG}$ sites correlates with age, and have formed the basis of epigenetic clock models of biological aging (Hannum et al., 2013). In humans, methylation states of specific genes appear to correlate well with biological age and link obesity and human immunodeficiency virus (HIV)-infection as accelerators of methylation and biological aging (Horvath et al., 2014; Gross et al., 2016). In fact, a 5-year increase in biological age as measured by epigenetic methylation results in a $21 \%$ increase in mortality risk (Marioni et al., 2015). Life span interventions such as calorie restriction and rapamycin, discussed later in this review, have previously been shown to reduce epigenetic age in mice, which show conserved $\mathrm{CpG}$ methylation sites (Wang et al., 2017).

\section{Core Physiological Functions in Aging Cardiovascular}

Cardiac output decreases by a rate of approximately $1 \%$ per year from the first decade of life, independently of cardiac disease. This is thought to occur through the senescence of cardiac muscle, decreased response of cardiac cells to glycosides and increased amyloid deposits with age (Steenman and Lande, 2017). These deposits also increase the prevalence of atherosclerosis and coronary artery disease in the elderly, severely affecting the cardiovascular system (Hansson, 2005). Alongside the respiratory and genito-urinary systems show reduced function with age as well as decreased immune function, leading to increased infection rates in the elderly (Kline and Bowdish, 2016; Nicolle, 2016; Chason et al., 2018). This suggests that several compartments of the immune system, including mucosal immunity, are altered in old age (Sala-Rabanal et al., 2015; Martelli et al., 2016).

\section{Central Nervous System}

Aging is associated with the development of numerous neuropathologies which appear exponentially with advancing age (Niccoli and Partridge, 2012). The accumulation of plaques in the brain has been associated with cognitive impairment and the development of Alzheimer's disease, whilst mitochondrial dysfunction is a causative factor in the appearance of Parkinson's disease (Pickrell and Youle, 2015; Snyder et al., 2015). In fact, the brain has been highlighted as particularly susceptible to aging. Dementia, an umbrella term for numerous neurodegenerative conditions, is a global issue affecting those from both lowincome and high-income countries, the prevalence of which is expected to double every 20 years going forward (Prince et al., 2013). Numerous causes have been attributed to the development of neurodegenerative disorders, such as dysregulated calcium signaling impacting on neuronal signaling, altered mitochondrial and ion channel dynamics affecting mid-brain cell survival in Parkinson's diseases and the contribution of "inflamm-aging" to neuroinflammation and decreased neuroplasticity (Di Benedetto et al., 2017; Frazier et al., 2017; Peng et al., 2018). Mitochondrial defects in particular have a large impact on neurological systems due to larger energetic requirements of the brain compared to other systems (Grimm and Eckert, 2017).

\section{Metabolic}

Progressive deterioration of the function of pancreatic beta cells and the development of insulin insensitivity causes one of the 
most prevalent age-related diseases, type 2 diabetes (Shaw et al., 2010; Marselli et al., 2014). Beta cells show reduced capacity to respond to glucose levels, resulting in reduced insulin output, reduced ability to control blood glucose levels and increased adiposity (Kahn, 2003). With adipocyte enlargement also comes a relative decrease in lean body mass due to muscle wastage (Kalinkovich and Livshits, 2017). This loss of muscle (sarcopenia) is due to the atrophy of muscle cells, generally as a consequence of a sedentary lifestyle. Sarcopenia together with frailty are two diseases that are highly associated with poor clinical outcomes such as increased fall incidence and hospitalization (Kramer et al., 2017). In parallel to muscle loss bone density is often reduced and hip-fracture is a classical condition of the elderly with poor balance and frailty (Kramer et al., 2017).

\section{Immune System}

Inflammation is a physiological process leading to the repair of tissues in response to exogenous and/or endogenous stress. However, it may establish a biological foundation of the pathophysiological process of frailty, since chronic inflammation generally induces detrimental consequences (Miller, 1996). Inflammation is frequently caused by an aged-related change in the immune system, known as immunosenescence. The chronic inflammation associated with immunosenescence is known as "inflamm-aging" which is accompanied by cytokine dysregulation. This phenomenon is marked by increased pro-inflammatory cytokine production and reduction in anti-inflammatory cytokines. The clinical consequences of this include increased risk of comorbidities such as bone, nutritional, and muscle metabolism disorders and mortality (Manolagas and Jilka, 1995; Cesari et al., 2004; Franceschi, 2007). Systemic inflammation was found to be implicated in the pathophysiology of neurodegenerative and cardiovascular disorders (Akiyama et al., 2000; Cesari et al., 2003; Lopez-Candales et al., 2017).

Aging affects aspects of both the adaptive and immune compartments of the immune system. Understanding of age-related changes in the adaptive immune system far outweighs that of the innate immune system (Montgomery and Shaw, 2015), with reductions in naive $\mathrm{T}$ cell pools and increases in memory pools with age observed for some time (Nikolich-Zugich, 2014). Generally $\mathrm{T}$ cell and $\mathrm{B}$ cell functions are reduced with age in many individuals, leading to reduced antibody production and $\mathrm{T}$ cell receptor (TCR) signaling defects in the elderly (Frasca et al., 2016; Le Page et al., 2018). Innate immune responses have also been shown to be dampened during ageing, alongside the development of a mature composition (Montgomery and Shaw, 2015). Additionally, there is a concurrent increase in the pro-inflammatory profile of the innate immune system leading to inflamm-aging (Bailey et al., 2018). The effects of aging on the major populations of immune cells varies greatly depending on cell type (Montgomery and Shaw, 2015). Monocytes isolated from elderly individuals display reduced cytokine production following toll-like receptor (TLR) activation with age and reduced interferon production, whilst dendritic cells show loss of antigen-cross presenting capacity (Chougnet et al., 2015; Metcalf et al., 2017; Molony et al., 2017). However, the innate immune system has also been shown to be activated at the basal level with aging (Molony et al., 2018). Reduction of the immune response to activation and increased basal activation of the adaptive and immune systems with age bring the concepts of immunosenescence and inflamm-aging together.

Not all systems become faulty with age in every individual, but most individuals will display one or more faulty system as they age. While loss or decreased function of organs may lead to mild symptoms and maintenance of autonomy and quality of life, failure of primary systems may have harsher consequences. The accumulation of senescent cells in various systems is thought to be the cause of their reduced functionality (Childs et al., 2015). Recent studies in genetically engineered mice suggest the specific removal of senescent cells (p16 expressing cells) as an efficient strategy to recover functions in older mice (Baker et al., 2011). One of these studies utilizes an INK-ATTAC transgene for inducible elimination of $\mathrm{p} 16^{\mathrm{INK} 4 \mathrm{~A}}$ expressing cells, a protein which is used as a biomarker for senescence and increases with ageing in both rodents and humans (Krishnamurthy et al., 2004). This transgene has been shown to reduce the onset of age-related disease in a progeroid mouse model when activated in a life-long and late-life manner, and reduced the functional decline of many organs (Baker et al., 2016; Bussian et al., 2018). Additionally, the senolytic drug ABT263, which selectively kills senescent cells in a B-cell lymphoma (BCL)-2/BCL-xL-dependent manner has shown promise reducing premature aging of the hematopoietic system in progeroid mice (Chang et al., 2016). This technique may also show promise in humans due to the fact that normal and induced-senescent human fibroblasts treated with a Forkhead box (FOX)O4 interfering peptide selectively targets senescent cells (Baar et al., 2017). This result has been confirmed in vivo in both normal aging and fast-aging mice which showed a reduction in the development of aging phenotypes compared to control treated mice (Baar et al., 2017). There is currently a series of efforts to test senolytics and aging-delaying drugs (Childs et al., 2018; Niedernhofer and Robbins, 2018). Limitations of these strategies (i) they are not targeted as they do not provide yet organ-specific removal of senescent cells (senolytics) and (ii) the aging-delaying drugs, including repurposed drugs (metformin, rapamycin) as well as novel ones (spermidine), have not yet been fully characterized for side-effects and aging-specific mechanisms of action (Aliper et al., 2017; Madeo et al., 2018).

In order to delay aging interventions may target its main hallmarks: genomic instability, telomere attrition, epigenetic alteration, loss of protein homeostasis, deregulated nutrient sensing, mitochondrial dysfunction, cellular senescence, stem cell exhaustion and altered intercellular communication (López-Otín et al., 2013). The unbalance in proteostasis has been suggested to be a significant player in the process of aging (Labbadia and Morimoto, 2015). Many upstream physiological systems such as ion channels function directly influence proteostasis as well as several other cellular processes (López-Otín et al., 2013; Hou et al., 2018). The same applies to mitochondria, an essential machinery linked to energy production and utilization in cells. The modulation of ion channel functions and mitochondrial activity are likely to have a wide range of effects depending on the cells/organs affected. The adaptation occurring during aging, and to some extent in senescent cells, has been described 
as a metabolic shift under intense mitochondrial influence (Wiley and Campisi, 2016). This further suggests aging and the accumulation of senescent cells to be driven by a metabolic shift and that modulation of the mitochondrial capacity may delay signs of aging. Hence, the control of essential systems such as ion channels and mitochondria would enable to reduce the pace of aging and promote healthspan. In this review, we focus on two aspects of cell physiology: ion channel biology and mitochondrial function that are interconnected and related to the majority of hallmarks of aging. Mitochondria have gained recent interest in the field of aging biology, especially since the discovery of autophagy and its role in proteostasis. Ion channel function is an overlooked phenomenon in the field of aging and this review aims to bring the attention to the topic.

\section{THE BIOLOGY OF ION CHANNELS IN AGING}

\section{Ion Channels Function and Dysfunction}

Ion channels represent a variety of transmembrane proteins forming pores. These pores are selective to specific ions able to actively cross between intracellular and extracellular compartments, therefore mediating the influx and efflux of charged ions (Kulbacka et al., 2017). Their large structural diversity at monomeric and heteromeric levels, due to alternative splicing, supports their large functional diversity. Each cell type represents an assemblage of ion channels that shape the amplitude and duration of the action potential differently (Hoppa et al., 2014; Rowan et al., 2016). At the intracellular level, ion channels are also present on the surface of the mitochondria, endoplasmic reticulum and nuclear membrane (Charpentier et al., 2016; Raffaello et al., 2016).

Since the first structural resolution of Potassium $\left(\mathrm{K}^{+}\right)$, Chloride $\left(\mathrm{Cl}^{-}\right)$and later on Sodium $\left(\mathrm{Na}^{+}\right)$channels by MacKinnon and Catterall research teams (Doyle et al., 1998; Dutzler et al., 2002; Payandeh et al., 2011), the biology of a large variety of ion channels has been well established. The development of a large set of biological small and active molecules targeting channels has been key to better understand their mechanisms of action and regulation (i.e., specific toxins, ligands, antibodies). About 400 annotated ion channel genes are retrieved in gene databases (about 1.5\% of the human genome). Behind several structural similarities, their modes of action differ depending on the involved ion, the ion channel gating and permeation pathway (Yang and Nerbonne, 2016; Latorre et al., 2017). They are classified into various voltage-gated $\left[\mathrm{Na}^{+}, \mathrm{K}^{+}, \mathrm{Cl}^{-}\right.$and Calcium $\left(\mathrm{Ca}^{2+}\right)$ ] and ligand-gated ion channels [nicotinic acetylcholine receptors (nAChRs), $\gamma$-amino butyric acid (GABA), $N$-methylD-aspartate receptors (NMDARs), ryanodine receptors (RyRs)] according to their electrophysiological properties and their depolarization events, neuronal signaling and contraction in response to depolarization. According to their electrochemical gradients, $\mathrm{Na}^{+}, \mathrm{K}^{+}$, and $\mathrm{Ca}^{2+}$ channels and their respective ions cross the membrane when depolarization is activated
(Bose et al., 2016). The electrophysiology reports of ion channel functions classify them into a large variety of subtypes according to their pharmacology and ionic properties, probably evolved from a common ancestor (Table 1). Despite this, chloride channels are distinctly classified as members of the voltage-sensitive subfamily with rarely predictable physiology [i.e., calcium-activated, high (maxi) conductance, cystic fibrosis transmembrane conductance regulator (CFTR) and volume regulated channels].

Malfunctioning and/or overexpression of ion channels has been observed in several healthy and tumor cells (Lan et al., 2005; Han et al., 2007). Dysfunctional calcium channel signaling has been observed in cognitive and cardiac decline, however, most of this research has so far been conducted in model organisms such as Drosophila (Lam et al., 2018; Navakkode et al., 2018). Within the atrio-ventricular region of rats sodium $\left(\mathrm{Na}_{\mathrm{v}} 1.5\right)$ are downregulated with age whilst calcium $\left(\mathrm{Ca}_{\mathrm{v}} 1.3\right)$ channels are upregulated, alongside augmented atrial-ventricular node functioning (Saeed et al., 2018). Similarly to this finding, an upregulation of L-type and osmotically activated calcium channels have been observed in human cardiomyopathy and aging, respectively (Jones et al., 2018; Sanchez-Alonso et al., 2018). An overview of ion channel dysfunctions and their relation to age-related disease is provided in Table 2. By controlling membrane potential and signal transduction pathways, ion channels on the surface of cells contribute to maintaining the proteostasis and homeostasis of systems. Therefore ion channels are incriminated in several age-related dysfunctions (Santulli and Marks, 2015; Rao et al., 2016). Because aging also involves physiological alterations of ion channel function, it is suggested that abnormal changes of ionic gradients can underlie age-dependent decline of physiological functions (Rao et al., 2016). With age, functional changes in ion channels lead to clinical phenotypes called channelopathies (Rao et al., 2016).

\section{Cardiac Channelopathies}

The vascular system often shows decline in a number of age-related diseases. Atherosclerotic plaques have been observed in humans from early life but often do not have a clinical impact until later in life (Jones et al., 2017). Several evidence has shown that both endothelium and smooth muscle cells (SMCs) communicate through signal transduction. Within the numerous changes that may occur at vascular and/or cardiac levels, it is noteworthy that voltage-dependent and $\mathrm{Ca}^{2+}$-activated $\mathrm{K}^{+}\left(\mathrm{BK}_{\mathrm{Ca}}\right)$ channels, abundant in vascular mural cell membranes, play an important role in vasodilatation and regulating coronary tone (Climent et al., 2017). In particular, they are activated by the vasodilator nitric oxide (NO). In age-related diseases, a reduction in the density of the $\mathrm{BK}_{\mathrm{Ca}}$ alpha subunit in coronary smooth muscle was observed to be associated with NO release (Toro et al., 2002) meaning a decreased expression during aging (Figure 1). Despite endothelial dysfunction, changes in $\mathrm{K}^{+}$channel expression and function are reported during aging in a young versus mature rat model (Simkin et al., 2015). Likewise, long-lasting L-type $\mathrm{Ca}^{2+}$ voltage dependent channels and high-conductance $\mathrm{BK}_{\mathrm{Ca}}$ 
TABLE 1 | Voltage-gated and ligand-gated ion channel nomenclature.

\begin{tabular}{|c|c|c|c|}
\hline $\begin{array}{l}\text { Gating } \\
\text { classification }\end{array}$ & Channel family & Channel subunit/subfamily & Channel abbreviation \\
\hline \multirow{12}{*}{$\begin{array}{l}\text { Voltage-gated ion } \\
\text { channel }\end{array}$} & Voltage-gated sodium channel $\left(\mathrm{Na}^{+}\right)$ & Alpha subunit & $\mathrm{Na}_{V} 1.1-1.9$ \\
\hline & & Beta subunit & Nav $\beta 1-4$ \\
\hline & Voltage-gated calcium channel $\left(\mathrm{Ca}^{2+}\right)$ & L-type calcium channel (Long-lasting) & Cav1.1-1.4 \\
\hline & & P/Q-type channel (Purkinje/Unknown) & Cav2.1 \\
\hline & & N-type channel (Neural) & Cav2.2 \\
\hline & & R-type channel (Residual) & Cav2.3 \\
\hline & & T-type channel (Transient) & Cav3.1-3.3 \\
\hline & Voltage-gated potassium channel & Alpha subunit & $\mathrm{K}_{\mathrm{V} 1-12}$ \\
\hline & & Beta subunit & $K_{v} \beta 1-3$ \\
\hline & $\begin{array}{l}\text { Hyperpolarization-activated cyclic } \\
\text { nucleotide-gated (CNG) channels }\end{array}$ & Alpha subunit & CNG $\alpha 1-4$ \\
\hline & & Beta subunit & CNG $\beta 1 / 3$ \\
\hline & Voltage-gated proton channels & Hydrogen channel & $\mathrm{H}_{V} 1$ \\
\hline \multirow[t]{13}{*}{$\begin{array}{l}\text { Ligand-gated ion } \\
\text { channel }\end{array}$} & lonotropic glutamate receptors & $\begin{array}{l}\alpha \text {-amino-3-hydroxy-5-methyl-4- } \\
\text { isoxazolepropionic acid receptor } \\
\text { (AMPA) }\end{array}$ & GluA1-4 \\
\hline & & Kainate & GluK1-5 \\
\hline & & N-methyl-D-aspartate receptor (NMDA) & $\begin{array}{l}\text { GluN1, NRL1A-B, GluN2A-D, } \\
\text { GluN3A-B }\end{array}$ \\
\hline & & Orphan & GluD1-2 \\
\hline & Cys-loop receptors & Serotonin $(5 \mathrm{HT})$ & 5-HT3A-E \\
\hline & & Nicotinamide acetylcholine (nAChR) & $\alpha 1-10, \beta 1-4, \gamma, \delta, \varepsilon$ \\
\hline & & Zinc-activated ion channel (ZAC) & ZAC \\
\hline & & Gamma-aminobutyric acid $(\mathrm{GABA})_{\mathrm{A}}$ & $\begin{array}{l}\alpha 1-6, \beta 1-3, \gamma 1-3, \delta, \varepsilon, \pi, \theta \\
\rho 1-3\end{array}$ \\
\hline & & Glycine (GlyR) & $\alpha 1-4, \beta$ \\
\hline & GABA receptors & $\mathrm{GABA}_{\mathrm{A}}$ receptor & $\alpha 1-6, \beta 1-3, \gamma 1-3, \delta, \varepsilon, \pi, \theta$ \\
\hline & $5-\mathrm{HT}_{3}$ receptor & Serotonin & $5-\mathrm{HT}_{3 \mathrm{~A}-\mathrm{E}}$ \\
\hline & ATP-gated channels & ATP-gated P2X receptor & $\mathrm{P} 2 \mathrm{X}_{1-7}$ \\
\hline & $\begin{array}{l}\text { Phosphatidylinositol 4,5-biphosphate } \\
\left(\mathrm{PIP}_{2}\right) \text {-gated channels }\end{array}$ & $\begin{array}{l}\text { Inwardly rectifying potassium channel } \\
\left(\mathrm{K}_{\mathrm{ir}}\right) \text {-activating }\end{array}$ & 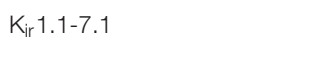 \\
\hline
\end{tabular}

channels are recognized as key regulators of vascular and arterial tone through the NO-cyclic guanosine monophosphate (cGMP) pathway (Climent et al., 2017). Their activities are modulated by intracellular $\mathrm{Ca}^{2+}$ and their abundance diminished with aging.

Therefore, vascular dysfunction is one of the main factors linked to age-related diseases including cardiovascular and cerebrovascular diseases. It occurs through a progressive alteration of the structure and/or function of the vasculature. Within the signaling pathway, ion channels modulate ion fluxes by either activating $\mathrm{K}^{+}$channels or inactivating $\mathrm{Ca}^{2+}$ channels leading to vasodilatation. In coronary smooth muscle during aging, a decrease in voltage- $\mathrm{Ca}^{2+}$-activated $\mathrm{K}^{+}$channels has been described (Marijic et al., 2001) and an inhibitory effect of testosterone has been demonstrated (Scragg et al., 2004). Beside endothelium-dependent mechanisms, hormones (i.e., testosterone, oestrogen) are involved in vasorelaxation via ion channel modulation and activating several signaling pathways (i.e., Phosphoinostide 3-kinase (PI3K)/Akt-dependent pathways) in vascular endothelial cells (Hisamoto et al., 2001). Both hormone receptors and $\mathrm{Ca}^{2+}$ voltage-gated channels are on the plasma membranes suggesting some commonalities in subsequent signaling pathways (Núñez et al., 2018). With this respect, ion channels are nowadays the preferential molecular targets of future drug developments and ion channel modulators are promising medicines to reduce human pathophysiological changes (Testai et al., 2015; Bhattacharya and Biber, 2016; O'Conor et al., 2016).

\section{Ion Channels in the Aging Nervous System}

Ion disturbance is present in neurological disorders associated with various types of voltage- and ligand-gated ion channel defects and/or mutations. For instance, implications of several voltage-gated sodium, potassium and calcium channel-subtype gene families are linked to dyskinesia, seizure, epilepsy, and ataxia pathogenesis (Simms et al., 2014). In neurons, changes in ionic fluxes occur very rapidly producing action potentials with fast depolarization, repolarization and signal propagation (Levitan and Kaczmarek, 2015). Neuronal signaling involves specific ion channels. The role of the ion channels in membrane physiology and brain homeostasis is essential, triggering nerve impulses and synaptic transmission. Many neurological disorders are 
TABLE 2 | lonic channels and their age-related diseases by blocker/ligand matches (Guide to Immunopharmacology portal, http://www.guidetopharmacology.org/).

\begin{tabular}{|c|c|c|c|}
\hline Ionic channel subtypes & Age related diseases & Blockers/ligands & Reference \\
\hline $\begin{array}{l}\text { Transient receptor potential } \\
\text { channels (TRP1, TRPM3) }\end{array}$ & $\begin{array}{l}\text { Polycystic kidney disease 2; } \\
\text { polycystic kidney disease 2-like } \\
1 \text { protein; }\end{array}$ & $\begin{array}{l}\text { No putative TRP1 blockers } \\
\mathrm{Cd}^{2+}, \mathrm{Ni}^{2+} \text { ligands }\end{array}$ & Oberwinkler et al., 2005 \\
\hline $\begin{array}{l}\text { Voltage-gated potassium } \\
\text { channels (Kv1.3) }\end{array}$ & $\begin{array}{l}\text { Autoimmune diseases (i.e., } \\
\text { diabetes, multiple sclerosis and } \\
\text { rheumatoid arthritis) }\end{array}$ & $\begin{array}{l}\text { Noxiustoxin; } \\
\text { Charybdotoxin; } \\
\text { Margatoxin } \\
\text { Kaliotoxin } \\
\text { Maurotoxin }\end{array}$ & $\begin{array}{l}\text { Grissmer et al., } 1994 \\
\text { Attali et al., } 1992 \\
\text { Garcia-Calvo et al., } 1993 \\
\text { Rochat et al., } 1998\end{array}$ \\
\hline $\begin{array}{l}\text { Voltage-gated calcium } \\
\text { channels }\left(\mathrm{Ca}_{\mathrm{v}} 1.4\right)\end{array}$ & $\begin{array}{l}\text { Ocular albinism, ocular albinism } \\
\text { type } 2\end{array}$ & $\begin{array}{l}\text { Dihydropyridine antagonists } \\
\text { (verapamil, diltiazem) }\end{array}$ & Baumann et al., 2004 \\
\hline $\begin{array}{l}\text { Calcium- and sodium-activated } \\
\text { potassium channels }\left(\mathrm{K}_{\mathrm{Ca}} 2.3\right)\end{array}$ & Parkinson disease & $\begin{array}{l}\mathrm{K}_{\mathrm{Ca}} 2.3 \text { blockers (Apamin, } \\
\text { Leiurotoxin I) }\end{array}$ & $\begin{array}{l}\text { Barfod et al., } 2001 \\
\text { Shakkottai et al., } 2001\end{array}$ \\
\hline $\begin{array}{l}\text { TRPV1 Transient receptor } \\
\text { potential channels }\end{array}$ & $\begin{array}{l}\text { Inflammatory bowel disease, } \\
\text { Chron's disease; Ulcerative } \\
\text { colitis }\end{array}$ & Agatoxin & Barfod et al., 2001 \\
\hline $\begin{array}{l}\text { TRPA1 Transient receptor } \\
\text { potential channels }\end{array}$ & $\begin{array}{l}\text { Inflammation, inflammatory pain } \\
\text { and inflammatory diseases }\end{array}$ & Divalent cations modulators & Nagata et al., 2005 \\
\hline $\begin{array}{l}\text { Cav2.2 Voltage-gated calcium } \\
\text { channels }\end{array}$ & $\begin{array}{l}\text { Renal and cardiovascular } \\
\text { diseases }\end{array}$ & Omega-conotoxins & Lewis et al., 2000 \\
\hline $\begin{array}{l}\text { Nav1.4 Voltage-gated sodium } \\
\text { channels }\end{array}$ & $\begin{array}{l}\text { Susceptibility to periods of } \\
\text { hyperactivity }\end{array}$ & $\begin{array}{l}\text { Saxitoxin } \\
\text { Tetrodotoxin } \\
\text { Mu-conotoxins } \\
\text { Lidocaine }\end{array}$ & $\begin{array}{l}\text { Penzotti et al., } 2001 \\
\text { Trimmer et al., } 1989 \\
\text { Safo et al., } 2000 \\
\text { Makielski et al., } 1999\end{array}$ \\
\hline $\begin{array}{l}\text { Kv8.1 Voltage-gated potassium } \\
\text { channels }\end{array}$ & Epileptic disease & $\begin{array}{l}\mathrm{K}_{\mathrm{v}} 8.1 \text { is not functional on its } \\
\text { own but modulates the } \\
\text { properties of coexpressed } \\
\mathrm{K}_{\mathrm{v}} 2.1\end{array}$ & Hugnot et al., 1996 \\
\hline $\begin{array}{l}\text { Cav1.3 Voltage-gated calcium } \\
\text { channels }\end{array}$ & Multiorgan disease & $\begin{array}{l}\mathrm{Cd}^{2+} \text {; Verapamil } \\
\text { dihydropyridine antagonist }\end{array}$ & Scholze et al., 2001 \\
\hline $\begin{array}{l}\text { Kv4.3 Voltage gated potassium } \\
\text { channels }\end{array}$ & $\begin{array}{l}\text { Àtrial Fibrillation, Valvular heart } \\
\text { disease }\end{array}$ & Phrixotoxin 1 & Wang et al., 2000 \\
\hline $\begin{array}{l}\mathrm{K}_{\mathrm{Ca}} 2.1 \text { Calcium- and } \\
\text { sodium-activated potassium } \\
\text { channels }\end{array}$ & $\begin{array}{l}\text { Ataxia, epilepsy, memory } \\
\text { disorders, pain and possibly } \\
\text { schizophrenia and Parkinsons's } \\
\text { disease }\end{array}$ & NS8593 gating inhibitor & Strobaek et al., 2006 \\
\hline $\begin{array}{l}\text { Nav1.6 Voltage-gated sodium } \\
\text { channels }\end{array}$ & Motor end-plate disease & $\alpha$ scorpion toxins & Oliveira et al., 2004 \\
\hline
\end{tabular}

caused due to altered function or mutation in ion channels (i.e., Alzheimer, Parkinson, Huntington, multiple sclerosis diseases) (Kumar et al., 2016). They are involved in propagation of action potential and secretion of neurotransmitters, therefore aberrant ion channels are considered of crucial negative influence in neurodegenerative disorders (Kumar et al., 2016). For instance, various calcium channels contribute to dysregulation of calcium homeostasis and play an important role in age-related changes (Navakkode et al., 2018). Recently, downregulation of the Cav3.1 T-type calcium channel has been demonstrated in N2a cells and the 3xTg-AD mouse model of Alzheimer's disease (Figure 1) (Rice et al., 2014).

Neurogenic inflammation and pain signaling are also mediated by specific members of the transient receptor potential (TRP) ion channel family. They are co-expressed in at least 25\% of nociceptors (Bautista et al., 2006; Pingle et al., 2007). For example, TRPA1 mediates the inflammatory actions of environmental irritants and analgesic agents and enhance pain and inflammation (Matta et al., 2008). The same
TRPA1 was shown to be activated in lung epithelial cells in response to cigarette smoke stress (Lin et al., 2015). This suggests some commonalities in the role of ion channels across various cell types and organs. Neuroinflammation and cognitive decline often appear concurrently in the aging brain, with inflammatory cytokines acting negatively on spatial memory (Blalock et al., 2003; Moore et al., 2009). The increased incidence of stroke with aging can bring about the production of inflammatory cytokines from microglia (Charolidi et al., 2015). Aging increases the production of interleukin (IL)-6 in the brain of aged mice, in a $\mathrm{K}_{\mathrm{V}}$ 1.3-dependent manner. Alongside this, microglia in aged mice show increased expression of voltage-activated $\mathrm{K}^{+}$channels, potentially enhancing IL-6 production and neuroinflammation with age (Schilling and Eder, 2015).

\section{Immuno-Channelopathies}

In innate and adaptive immunity, regulation of membrane potential and calcium influx are determined by the equilibrium 

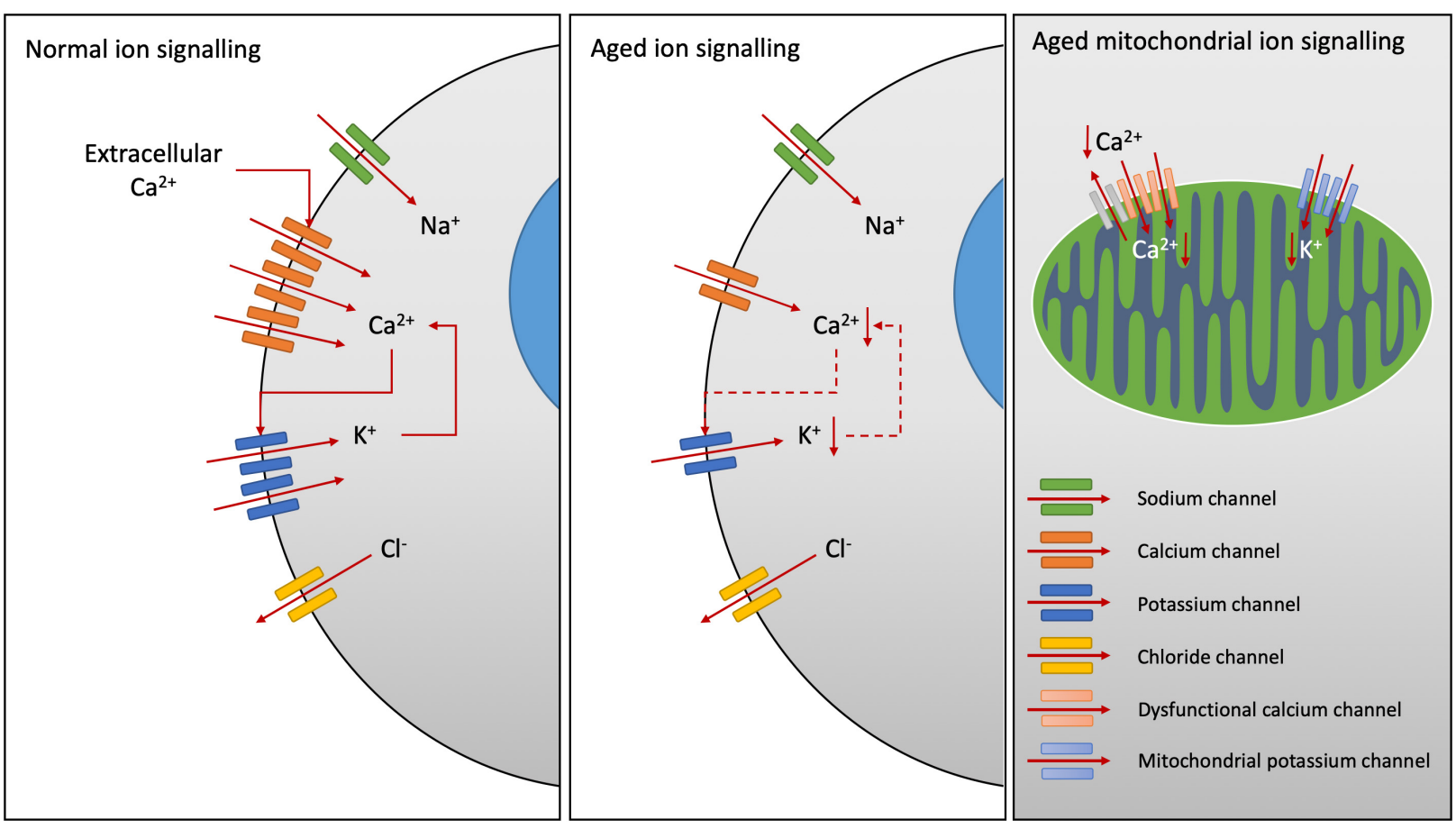

FIGURE 1 | Age-related changes in ion channel function. Calcium $\left(\mathrm{Ca}^{2+}\right)$ release-activated $\mathrm{Ca}^{2+}$ channels increase intracellular Ca ${ }^{2+}$ levels, activating $\mathrm{K}^{+}$channel opening and sustained $\mathrm{Ca}^{2+}$ signaling, whilst efflux of chloride $\left(\mathrm{Cl}^{-}\right)$ions inhibits $\mathrm{Ca}^{2+}$ influx. Downregulation of Ca ${ }^{2+}$ channels has been demonstrated in Alzheimer's disease. Decreased expression of $\mathrm{Ca}^{2+}$-activated $\mathrm{K}^{+}$channels have been noted with aging, particularly within the smooth muscle cells of the vascular system reducing arterial tone. Within the mitochondria, reduced $\mathrm{Ca}^{2+}$ ion channel activity results in reduced Ca ${ }^{2+}$ cycling. Potassium channel expression on the mitochondria are also reduced with age in the heart sarcolemma.

potentials of $\mathrm{K}^{+}\left(\mathrm{K}_{\mathrm{V}} 1.3, \mathrm{~K}_{\mathrm{Ca}} 3.1\right), \mathrm{Na}^{+}(\mathrm{TRPM} 4)$ and $\mathrm{Cl}^{-}$ channels in the plasma membrane (Feske et al., 2015). Following $\mathrm{T}$ cell activation, opening of Orai (the store-operated calcium channel) that encodes $\mathrm{Ca}^{2+}$ release-activated $\mathrm{Ca}^{2+}$ (CRAC) channels (also expressed in B cells, NK cells, macrophages, DCs, neutrophils) results in $\mathrm{Ca}^{2+}$ influx and subsequent opening of $\mathrm{K}_{\mathrm{Ca}} 3.1$ and $\mathrm{K}_{\mathrm{V}} 1.3$ channels (Figure 1) (Feske et al., 2015). The study of mechanisms underlying their function in lymphocytes, using ion channel inhibitors, revealed important roles of ionic signals in immune responses. For instance, the open state of $\mathrm{K}_{\mathrm{Ca}} 3.1$ and $\mathrm{K}_{\mathrm{V}} 1.3$ channels mediate $\mathrm{K}^{+}$efflux and hyperpolarization of the plasma membrane, thereby sustaining $\mathrm{Ca}^{2+}$ influx (Figure 1). Alongside this, opening of $\mathrm{Cl}^{-}$channels results in efflux of $\mathrm{Cl}^{-}$ions that inhibits $\mathrm{Ca}^{2+}$ influx (Feske et al., 2015). Altered immune function through ion signaling can have profound effects on the development of age-related disease. Necrosis in the tumor microenvironment, which causes release of $\mathrm{K}^{+}$ions into the extracellular space, has recently been shown to reduce effector $\mathrm{T}$ cell function in a TCR-dependent manner (Eil et al., 2016). Additionally, the activation of acid-sensing ion channels in microglia following stroke has been shown to increase the development of neuroinflammation in rats, tying ion signaling in immune cells to inflamm-aging (Yu et al., 2015).

\section{ION CHANNELS, MITOCHONDRIA AND AGING}

\section{Ion Channels Regulate Mitochondrial Functions}

Mitochondria are often referred to as the powerhouse of the cell, however, their physiological role goes well beyond that (Chandel, 2015; Vakifahmetoglu-Norberg et al., 2017). Mitochondria are highly dynamic organelles regulating their structure in line with metabolism, redox signaling, mitochondrial deoxyribonucleic acid (DNA) maintenance and apoptosis (Vakifahmetoglu-Norberg et al., 2017). Besides from generating adenosine triphosphate (ATP) for cellular energy, mitochondria are also deeply involved in providing intermediates for cellular signaling and proliferation (Diebold and Chandel, 2016). Mitochondria can alter their size and organization as a result of mitochondrial fission and fusion in response to various intracellular and extracellular signals (Seo et al., 2010). Fission and fusion events occur to meet metabolic demands and for the removal of damaged/dysfunction mitochondria. The role of mitochondrial fission and fusion in facilitating metabolism has been researched extensively (Wai and Langer, 2016). Fused mitochondrial networks typically engage more oxidative pathways of metabolism, whilst fragmentation as a result of stress 
impairs the oxidative pathway and increases cellular demand on glycolysis (Wai and Langer, 2016).

Ion channels are intimately involved in regulating mitochondrial function (O'Rourke, 2007). The essential role of cationic hydrogen $\left(\mathrm{H}^{+}\right)$ion transfer in ATP production was noted as early as 1961 (Mitchell, 1961). $\mathrm{H}^{+}$ions are pumped from the mitochondrial matrix into the intermembrane space by the flow of electrons through the electron transport chain. These ions are then utilized to drive the ATPase machinery and phosphorylate ATP, thus creating energy for the cell (Mitchell, 1961). The movement of ions across the mitochondrial membrane is also essential in establishing membrane potential and maintaining proton $\left(\mathrm{H}^{+}\right)$flux. Ions transported across the inner membrane include potassium $\left(\mathrm{K}^{+}\right)$, sodium $\left(\mathrm{Na}^{+}\right)$ and calcium $\left(\mathrm{Ca}^{2+}\right)$, alongside $\mathrm{H}^{+}$(O'Rourke, 2007). The most well-studied ion channel within the mitochondrion is the voltage-dependent anion channel, also known as VDAC, which is the primary route of metabolite and ion exchange across the outer mitochondrial membrane (Colombini, 2004).

Mitochondrial channelopathies have been found in aging, affecting the $\mathrm{K}^{+}, \mathrm{Ca}^{2+}$, VDAC and permeability transition pore $\left(\mathrm{Ca}^{2+}\right.$; PTP) channels. Mitochondrial $\mathrm{Ca}^{2+}$ cycling is impaired with aging in neurons, resulting from reduced $\mathrm{Ca}^{2+}$ channel activity and reduced recovery after synaptosomal stimulation (Figure 1) (Satrustegui et al., 1996). This reduced calcium recovery rate results in reduced mitochondrial membrane potential and delayed repolarization, causing mitochondrial dysfunction with aging. This effect has been found in the heart of 2 year old senescent rats (Jahangir et al., 2001). In terms of potassium channels, it has been shown that their density on the surface of mitochondria significantly declines with age and with metabolic syndromes in the heart sarcolemma (Figure 1) (Ranki et al., 2002; Truong et al., 2016). This has been shown to reduce tolerance to ischemia-reperfusion and increased injury in aged guinea pig and rat hearts, and also humans (Roscoe et al., 2000; Kamada et al., 2008). These effects have repercussions in increasing susceptibility to myocardial infarction and reducing neuronal activity in the elderly as mitochondrial $\mathrm{K}^{+}$channels have been shown to play a neuroprotective role in neurological reperfusion injury in postnatal mouse pups (Connors et al., 2015). Amyloid- $\beta$ plaques in Alzheimer's disease have been shown to increase intracellular calcium levels (Demuro et al., 2011). This increase in intracellular calcium, and uptake into the mitochondria through the VDAC and calcium uniporter, has been shown to increase mitochondrial stress responses and initiate apoptosis in rat cortical neurons in vitro and hippocampal slices ex vivo (Alberdi et al., 2010). Recent studies in Parkinson's disease, have revealed that $\alpha$-synuclein acts via the VDAC to promote mitochondrial toxicity of respiratory chain components in a yeast model of Parkinson's (Rostovtseva et al., 2015).

\section{Mitochondrial Dysfunctions in Aging}

In-born errors of metabolism and mitochondrial defects can have wide-spread effects on human physiology from birth (Vernon, 2015). These mitochondrial disorders are commonly characterized by symptoms such as vision loss, heart disease and dementia similar to that seen during aging, highlighting the crucial role of mitochondria in maintaining cellular and physiological function (Ganesh et al., 2017; Towbin and Jefferies, 2017; Sklirou and Lichter-Konecki, 2018). The onset of age-related pathologies have been linked to the development of mitochondrial dysfunction for some time, particularly in the development of Parkinson's disease (Abou-Sleiman et al., 2006). Moreover, mitochondrial dysfunction has also been observed in cardiac disease, Alzheimer's disease and more recently diabetic kidney disease (Lesnefsky et al., 2001; Reddy and Beal, 2008; Qi et al., 2017). Therefore, it is not hard to see the correlation between increasing mitochondrial dysfunction and the decline in physiological systems with aging. In fact, mitochondrial dysfunction was highlighted as one of the nine hallmarks of aging (López-Otín et al., 2013). Mitochondrial dysfunction manifests during normal aging, its aggravation accelerates aging and its amelioration in model organisms increases life span.

Mitochondrial biogenesis resulting from the growth and division of existing organelles maintains mitochondrial health and integrity, however, this process has been shown to be reduced with age in both animals and humans (Figure 2) (López-Lluch et al., 2008; Srivastava, 2017). The rate of loss of mitochondrial biogenesis with age is still argued, however, it has been shown to be augmented in response to physiological stimuli such as hormones and transcription factors. For example, oestrogen and progesterone promote whilst testosterone inhibits mitochondriogenesis in human brown adipose tissue in vitro, whilst the nuclear respiratory transcription factors (NRF1 and NRF2) influence the expression of mitochondrial respiratory genes (Rodriguez-Cuenca et al., 2007; Scarpulla et al., 2012).

Additionally, exercise and caloric restriction have been shown to enhance mitochondrial biogenesis whilst obesity and type 2 diabetes, which are prevalent in the aging population, have been shown to reduce it (Hebert et al., 2013; Heinonen et al., 2015). These mechanisms act directly by augmenting the expression of the mitochondrial biogenesis regulator peroxisome proliferator-activated receptor gamma coactivator 1 -alpha (PGC-1 $\alpha)$ and indirectly by mediating the activation of adenosine monophosphate-activated kinase (AMPK) which phosphorylates PGC-1 $\alpha$ (Jager et al., 2007; Jornayvaz and Shulman, 2010). The PGC-1 $\alpha$ transcriptional coactivator in line with NRF1 and NRF2 regulates the expression of nuclear encoded mitochondrial proteins (Lin et al., 2005). Hormone receptors including peroxisome proliferator-activated receptors alpha and gamma and oestrogen related receptor alpha also regulate the expression of mitochondrial genes in concert with PGC-1 $\alpha$ (Lin et al., 2005). In response to stress AMPK induces mitophagy by inhibiting mammalian target of rapamycin (mTOR), whilst Sirtuin-1 phosphorylation by AMPK activates PGC- $1 \alpha$ and stimulates mitochondrial biogenesis (Rodgers et al., 2005; Alers et al., 2012). In rats, reduced AMPK activity has been linked to reduced mitochondrial biogenesis and insulin resistance with age (Reznick et al., 2007; Qiang et al., 2007). Whilst caloric restriction has been shown to increase PGC-1 $\alpha$ activity in primary rat hepatocytes (López-Lluch et al., 2006), the effect of caloric restriction on AMPK activity is under discussion with studies reporting both positive and negative results on AMPK signaling 
depending on the disease model studied (García-Prieto et al., 2015; Amaral et al., 2016; Bayliss et al., 2016).

During aging, the efficiency of mitochondrial electron transport chain weakens, thus reducing cellular ATP production and increasing electron leakage and reactive oxygen species (ROS) production in model organisms such as Caenorhabditis elegans and Drosophila (Figure 2) (Ferguson et al., 2005; Rea et al., 2007; Chistiakov et al., 2014). However, studies of human aging are conflicted over the relationship between electron transport chain activity and aging (Parker et al., 1989; Barrientos et al., 1996; Doria et al., 2012). Mitochondria have formed the basis of a number of theories examining the phenomenon of aging, the most well-studied and accepted being the free-radical theory of aging (Harman, 1992). This theory focuses on the increased production of ROS with age which causes progressive cellular damage (Figure 2). As ROS originate from the mitochondria, these powerful and essential organelles are the most susceptible to this oxidative damage (Belhadj Slimen et al., 2014). Mutations in mitochondrial DNA have previously been linked to impaired mitochondrial function and apoptosis in both murine and human brain and muscle tissue (Fayet et al., 2002; Kraytsberg et al., 2006; Li H. et al., 2017). This results in impaired tissue homeostasis, degeneration and the development of age-related phenotypes such as sarcopenia and neurodegeneration (Cha et al., 2015; Herbst et al., 2016). Whilst ROS have been linked to the increase in mitochondrial DNA mutations with aging, this phenomenon can occur in the absence of oxidative stress and has been attributed to replication errors (Seo et al., 2010; López-Otín et al., 2013). Additionally, the free radical theory of aging has recently been brought into question through studies in the model organism C. elegans. Here, more recent studies have shown that the absence of the antioxidant superoxide dismutase (SOD) does not affect lifespan unless the organism is put under stress (Van Raamsdonk and Hekimi, 2012). Loss of SOD2 specifically has been shown to increase lifespan in clk-1 ETC (Coenzyme Q) mutants whilst decreasing lifespan in isp-1 ETC (complex II) mutant worms (Van Raamsdonk and Hekimi, 2009). Additionally, mitochondrial ROS production is required for longevity in the C. elegans isp-1 and nuo-6 ETC mutants by protecting against mitochondrial dysfunction (Yee et al., 2014).

A pro-oxidative redox state has been implicated in the development of cardiovascular disease, inflammation, diabetes, neurodegeneration and cancer in human health (del Valle, 2011; Dai et al., 2014; Münzel et al., 2015). ROS have extensive effects within the cellular environment causing protein misfolding and aggregation, as well as oxidative damage to DNA (Nakamura and Lipton, 2017). Parkinson's disease results from abnormalities in the expression of the protein Parkin, which aids in the autophagic degradation of dysfunctional and damaged mitochondria (Kazlauskaite and Muqit, 2015). Loss of this protein with age in humans and mice results in decreased autophagy of mitochondria (mitophagy), leading to the accumulation of damaged organelles, decreased function and neurodegeneration (Song et al., 2017; Zanon et al., 2017). A similar process has been observed in Alzheimer's disease, where amyloid- $\beta$ plaque accumulation leads to mitochondrial dysfunction and cellular toxicity. Studies in yeast have helped to delineate the mechanism behind this effect on mitochondrial function, whilst amyloid- $\beta$ has also been shown to induce mitochondrial dysfunction in human neural stem cells (Mossmann et al., 2014; Chiang et al., 2016).

\section{ROLE OF MITOCHONDRIA IN THE REGULATION OF INFLAMM-AGING}

\section{Inflammation and Age-Related Diseases}

It is well established that there is an age-related dysregulation of pro/anti-inflammatory circulating cytokines which are increased threefold to fourfold in plasma or serum from elderly participants, termed inflamm-aging. Several studies have reported that this cytokine-related aging process appears to be related to a collection of age-related syndromes, including loss of muscle and bone mass, anemia, immune dysfunction and memory decline (Morley and Baumgartner, 2004; Reale, 2014). Westendorp has reported that persons with high levels of tumor necrosis factor alpha (TNF $\alpha$ ) and low levels of IL-10 favor a protective role in infection and will have an extended lifespan, thus suggesting that the balance between pro- and anti-inflammatory cytokines influences longevity (Westendorp, 2004). However, the burden of disease has now shifted away from infectious diseases toward the chronic diseases that typically come with old age. In this regard IL- 6 has been linked to the aging process and has been named the "geriatric cytokine" (Herpich et al., 2018). Muscle wastage and high mortality are associated with elevated serum levels of IL-6 in the elderly (Forcina et al., 2018; Ridker et al., 2018). For example, a one SD increase in IL-6 levels in elderly patients results in a $1.1-2.3 \mathrm{~kg}$ loss in grip strength, whilst acute injection of IL-6 in rats causes a $17 \%$ loss of myofibrillar protein (Visser et al., 2002; Haddad et al., 2005). This age-associated increase in production of IL-6 was recently proposed to be linked to the process of cellular senescence. Senescent cells, which number increases with aging, were shown to have a pro-inflammatory secretory profile, including IL-6, which is part of the senescence associated secretory phenotype (SASP) (Watanabe et al., 2017). Alongside IL-6 the concentration of TNF $\alpha$, a pro-inflammatory cytokine produced by macrophages and adipocytes, is significantly increased in centenarians compared with younger subjects (Bruunsgaard et al., 1999; Holmes et al., 2009). This increase was associated with a greater incidence of both Alzheimer's disease and generalized atherosclerosis in centenarians (Bruunsgaard et al., 1999; Holmes et al., 2009). This chronic, sterile, low-grade inflammation called inflamm-aging contributes to the pathogenesis of age-related diseases such as those summarized in Table 3. SASP cytokines such as IL- 6 and TNF $\alpha$ are regulated by molecules such as IL-10 (Stenvinkel et al., 2005). The interaction between pro- and anti-inflammatory molecules is complex and in the context of cardiovascular disease strongly suggests that dysregulation of this interplay may lead to complications such as end stage renal disease.

Recent advances have shown that the pro-inflammatory capacity of cells is regulated by the inflammasome (Guo et al., 2015). The inflammasome is a multiprotein 
TABLE 3 | Cytokines and their age-related-diseases.

\begin{tabular}{|c|c|c|c|}
\hline $\begin{array}{l}\text { Age-related- } \\
\text { diseases }\end{array}$ & $\begin{array}{l}\text { Principal } \\
\text { associated }\end{array}$ & cytokine & Reference \\
\hline Sepsis & $\uparrow$ IL-6 level & $\rightarrow \uparrow$ risk & Starr and Saito, 2014 \\
\hline \multirow[t]{2}{*}{ Alzheimer disease } & $\begin{array}{l}\uparrow I L-6 \text { Level } \\
\uparrow I L-1 \beta \text { level }\end{array}$ & $\rightarrow \uparrow$ risk & $\begin{array}{l}\text { Banks and Morley, } 2003 \\
\text { Wilson et al., } 2002 \\
\text { Licastro et al., } 2000\end{array}$ \\
\hline & $\downarrow$ G-CSF & $\rightarrow \uparrow$ risk & Barber et al., 2012 \\
\hline Cachexia syndrome & $\uparrow T N F \alpha$ level & $\rightarrow \uparrow$ risk & $\begin{array}{l}\text { Baez-Franceschi and } \\
\text { Morley, } 1999\end{array}$ \\
\hline $\begin{array}{l}\text { Dilated } \\
\text { cardiomyopathy }\end{array}$ & $\uparrow \mathrm{TNF} \alpha$ level & $\rightarrow \uparrow$ risk & Levine et al., 1990 \\
\hline $\begin{array}{l}\text { Atherosclerosis and } \\
\text { osteopenia }\end{array}$ & $\begin{array}{l}\uparrow I \mathrm{~L}-6 \text { level } \\
\uparrow \mathrm{TNF} \alpha \text { level } \\
\uparrow \mathrm{IL}-1 \beta \text { level }\end{array}$ & $\rightarrow \uparrow$ risk & $\begin{array}{l}\text { Hak et al., } 2000 \\
\text { Jørgensen et al., } 2001\end{array}$ \\
\hline Cognitive decline & $\begin{array}{l}\uparrow I L-6 \text { level } \\
\uparrow T N F \alpha \text { level }\end{array}$ & $\rightarrow \uparrow$ risk & $\begin{array}{l}\text { Engelhart et al., } 2004 \\
\text { Schram et al., } 2007 \\
\text { Weaver et al., } 2002\end{array}$ \\
\hline \multirow[t]{2}{*}{ Acute stroke } & $\begin{array}{l}\uparrow I L-6 \text { level } \\
\uparrow T N F \alpha \text { level }\end{array}$ & $\rightarrow \uparrow$ risk & $\begin{array}{l}\text { Jung et al., } 2010 \\
\text { Stankowski and Gupta, } \\
2011\end{array}$ \\
\hline & $\begin{array}{l}\uparrow \text { IL-10 level } \\
\uparrow \mathrm{TGF}-\beta \text { level }\end{array}$ & $\rightarrow \downarrow$ risk & $\begin{array}{l}\text { Van Exel et al., } 2002 \\
\text { Pang et al., } 2001\end{array}$ \\
\hline
\end{tabular}

intracellular complex that forms in response to stress (pathogenic microorganisms/sterile stressors) and results in the release of the pro-inflammatory cytokines IL-1 $\beta$ and IL-18 (Guo et al., 2015). IL- $1 \beta$ induces IL-2 and TNF $\alpha$ through the activation of T-helper cells, and produces tissue inflammatory actions by activating cyclooxygenase- 2 to produce prostaglandin E2, inducible intercellular adhesion molecules and NO (Raeburn et al., 2002). IL-1 $\beta$ causes fever, anorexia, sickness behavior and a decline in the ability to acquire and retain memory in mice (Banks et al., 2001). It was also reported that IL-1 $\beta$ may increase the production of amyloidal precursor protein within the central nervous system and the development of neurodegenerative disorders such as Alzheimer's disease, with increased plasma levels of pro-inflammatory cytokines IL- 1 and IL- 6 also observed in these patients (Licastro et al., 2000; Wilson et al., 2002; Banks and Morley, 2003; Shaftel et al., 2008).

Age-related inflammation has recently been postulated as a concomitant adaptation to the metabolic shifts observed during aging (Franceschi et al., 2018). This metabolic shift toward decreased mitochondrial respiration and increased glycolysis is observed within the model organism C. elegans (Feng et al., 2016), as well as in rat hepatocytes and human skeletal muscle (Hagen et al., 1997; Gouspillou et al., 2014). In aging bone, impaired oxidative metabolism leading to a glycolytic shift has been identified in mice due to PTP opening and mitochondrial dysfunction (Shum et al., 2016). However, human fibroblasts from aged individuals display a decrease in glycolytic flux and lactate output and increase in oxygen consumption rate and ATP levels (Son et al., 2017), suggesting this age-related metabolic shift may be tissue specific. This metabolic adaptation and concurrent inflammation with age is thought to result in chronic inflammation driven by nutrient excess, obesity and regulated by gut microbiota (Franceschi et al., 2018). This is supported by the fact $\mathrm{TNF} \alpha$ promotes anorexia, stimulates lipolysis and inhibits lipoprotein lipase, leading to cachexia syndrome in older persons. This implicates cytokines in feeding behavior and their effects in the elderly (Baez-Franceschi and Morley, 1999). This meta-inflammation hypothesis supports the potential role of mitochondria, an essential keychain of the metabolic regulations, in driving age-related inflammation. As discussed above (i) mitochondria are involved in immune-metabolic adaptation (ii) mitochondrial dysregulation is a core hallmark of aging and senescence (iii) mitochondrial functions rely highly on ion channel biology. Altogether this suggests an unexplored role of ion channels in the regulation of inflammation.

\section{Ion Channels, Mitochondria and SASP Immune Cells}

It has been more than 30 decades since expression of ion channels in non-excitable immune cells (i.e., T lymphocytes) was first described (DeCoursey et al., 1985). Besides their role in cell excitability, $\mathrm{K}_{\mathrm{V}}$ channels are also involved in regulating cellular secretion and in the differentiation and growth of non-excitable cells. In particular, $K_{V}$ channels have been implicated in the proliferation of many cell types and are usually down- or up-regulated in immune cells of patients with cancerous diseases (Pardo, 2004; Pardo et al., 2005). On the surface of immune cells, a variety of ion channel subtypes are displayed. $\mathrm{K}_{\mathrm{V}} 1.3$ are the most well-described potassium channel subtype involved in the inflammation process and their dysfunction is associated to altered $\mathrm{T}$ function, through impacting the calcium influx and contributing to age-related changes of $\mathrm{T}$ cell function (Kollár et al., 2015).

The most recent advances in the field of senescence, aging and inflammation relate to the concept of the SASP. SASP refers to the increased secretion of inflammatory cytokines, chemokines and growth factors secreted by senescent cells (Watanabe et al., 2017). The most common group of secreted SASP factors are the major pro-inflammatory cytokines IL-1 $\beta$, IL-6 and IL-8, produced via augmented NF-кB and mTOR signaling in senescent human fibroblasts and embryonic kidney cells (Chien et al., 2011; Herranz et al., 2015). A causal relationship between systemic inflammation and the prevalence of generalized age-related osteoporosis has been observed in the elderly (Yun and Lee, 2004; Ginaldi et al., 2005). Inflammatory cytokines such as IL- 6, TNF- $\alpha$ and IL-1 $\beta$ produced through SASP (Watanabe et al., 2017), are stimulators of osteoclast activity and are linked to the development of atherosclerosis and osteopenia (Hak et al., 2000; Jørgensen et al., 2001). SASP factors have simultaneously been shown to affect injury recovery. Low levels of IL-6 were significantly correlated with better functional and muscular recovery after femoral neck fracture in women of good health aged 65 and over (Miller et al., 2006, 2008).

Activation of inflammasomes, particularly the nod-like receptor P3 (NLRP3) inflammasome, is highly dependent on the activity and integration of the mitochondria. The mitochondrial antiviral signaling protein (MAVS) adaptor is required for recruitment of NLRP3 to the mitochondria and its activation (Figure 3B), whilst the endoplasmic reticulum-mitochondrial 
junction is also integral to inflammasome activation (Raturi and Simmen, 2013; Subramanian et al., 2013). Dysfunctional mitochondria have been linked to inflammation for some time, and have also been implicated in the inflamm-aging process
(Picca et al., 2017). Damage-associated molecular patterns (DAMPs) accumulate with age as a result of the release of ROS and ATP from damaged mitochondria (Kapetanovic et al., 2015). Although mitochondria have been present in animal

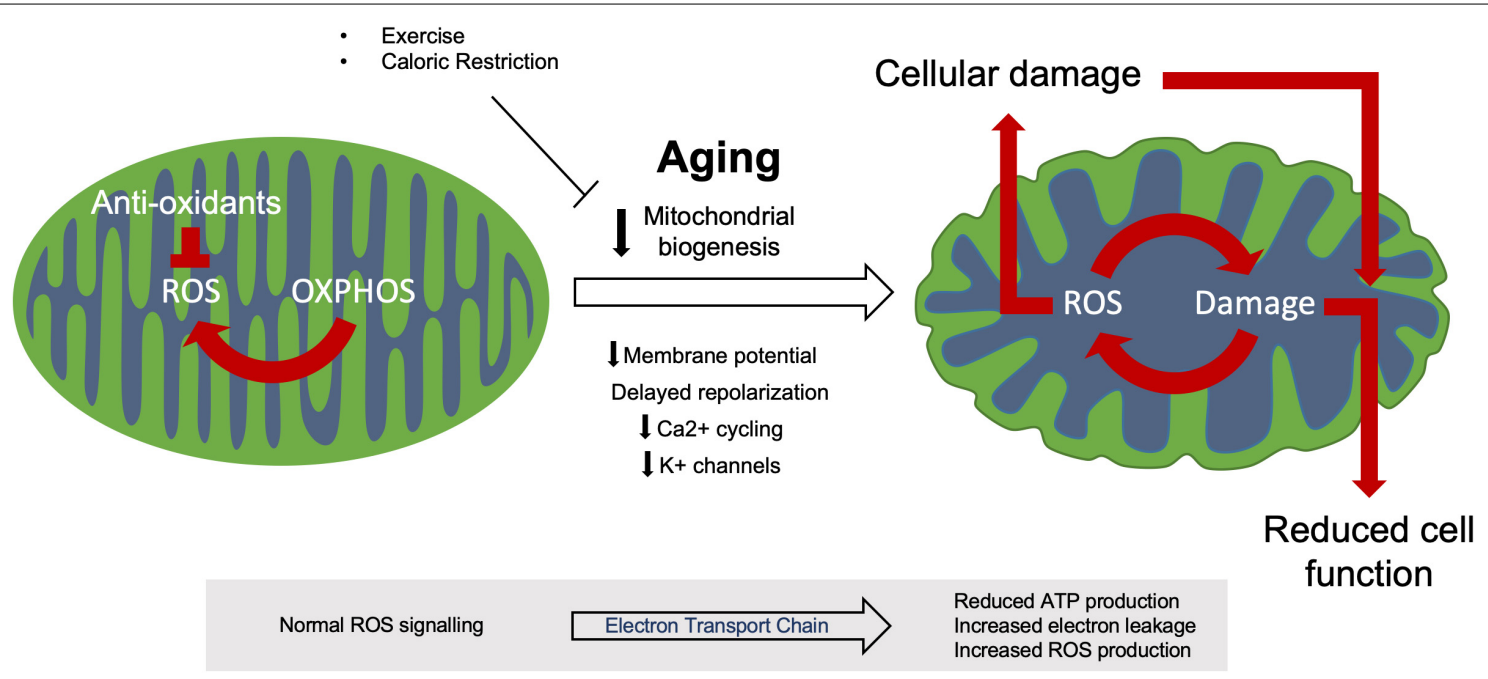

FIGURE 2 | Mitochondrial dysfunction during aging. Healthy mitochondria produce ROS through regular oxidative (OXPHOS) activity which aid in normal cell processes, this ROS production is kept in check by various anti-oxidant systems to prevent oxidative damage. During aging, dysfunctional mitochondria accumulate due to reduced biogenesis and ROS control. This increased ROS production induces both further mitochondrial damage and cellular damage, resulting in reduced cell function and eventual apoptosis.

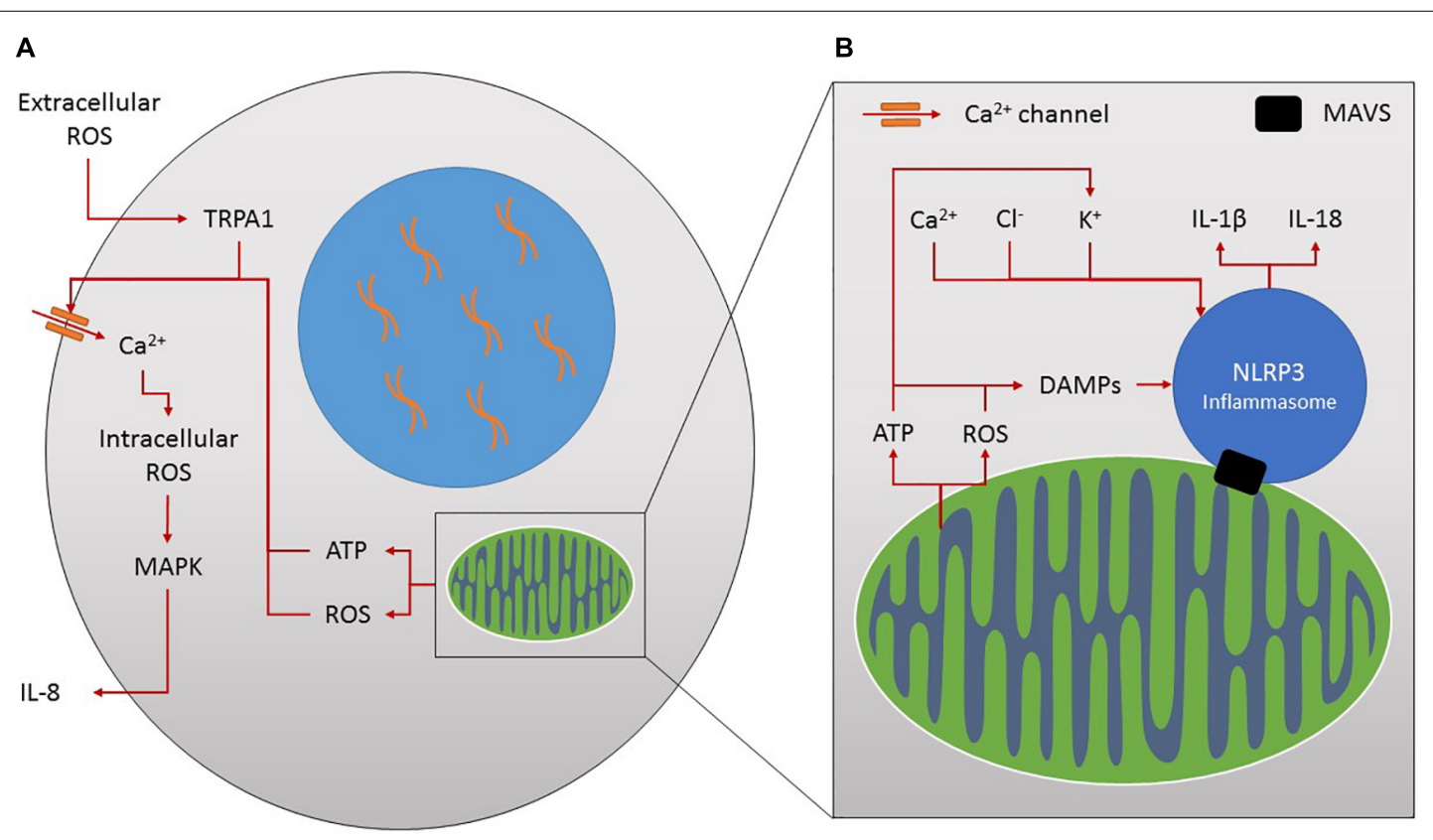

FIGURE 3 | (A) lon channels and inflammation. Increased extracellular reactive oxygen species (ROS) stimulates TRPA1 and calcium (Ca $\left.{ }^{2+}\right)$ influx. This increases intracellular ROS production, MAPK activation and pro-inflammatory IL-8 release. Mitochondria produce ROS and ATP through their normal activities which affect ion flux, for example by increasing calcium influx into the cell by increasing calcium ion channel activity and stimulating further ROS production. In turn the secretion of inflammatory molecules such as IL-8 is stimulated. (B) Mitochondria, ions and inflammation. Mitochondria form the major platform for NLRP3 inflammasome assembly through the mitochondrial antiviral signalling protein (MAVS). Mitochondria activate this inflammasome complex by releasing damage associated molecular patterns (DAMPs) such as ROS and ATP leading to the maturation of IL-1 $\beta$ and IL-18 inflammatory molecules. Similarly, increased influx of ions such as calcium, chloride and potassium can also influence inflammasome activation. 
cells for millions of years, it is believed that mitochondria originated from bacteria and can be seen by the body as pathogen-associated molecular patterns (PAMPs) (Krysko et al., 2011). Both DAMPs and PAMPs induce an immune response by triggering the activation of inflammasomes, including the NLRP3 inflammasome in innate immune cells such as macrophages, driving maturation of IL-1 $\beta$ and IL-18 pro-inflammatory cytokines (Figure 3B) (Kapetanovic et al., 2015).

It is also tempting to speculate on the role of ion channels in the activation of the inflammasome. Potassium and chlorine efflux, alongside calcium influx, have been shown to influence NLRP3 inflammasome activation (Figure 3B) (Jo et al., 2016; Hafner-Bratkovic and Pelegrin, 2018). ATP, as a common activator of NLRP3, induces decreased levels of potassium and alters other ionic contents within the cell (Jo et al., 2016), essential for inflammasome activation in monocytes/macrophages (Petrilli et al., 2007). In fact the intracellular chloride channel has been shown to act downstream of potassium efflux, as a result of mitochondrial ROS generation, to promote NLRP3 activation in murine macrophages and a human monocytic cell line (Tang et al., 2017). Inflammasome activation itself has also been shown to affect potassium, chlorine and calcium homeostasis contributing to cytokine release in cells of the innate immune system (Perregaux and Gabel, 1994; Hafner-Bratkovic and Pelegrin, 2018). Chronic inflammation, Alzheimer's disease and metabolic diseases such as Type 2 diabetes have been linked to aberrant activation of the NLRP3 inflammasome by damaged mitochondria and dysregulated ion flux (Jo et al., 2016). Therapeutic interventions to modulate the adverse and overlapping effects of the numerous different inflammatory mediators on each ion transport system could target adversely affected ion transport systems directly and locally.

\section{Other Cells}

The expression or function of most ion channels can be modulated by cytokines, prostaglandins, leukotrienes and ROS resulting from inflammation. Key pathways in this interaction are cyclic nucleotide, phosphoinositide and mitogen-activated protein kinase (MAPK)-mediated signaling, direct modification by ROS-like NO, ATP or protons and disruption of the cytoskeleton in neuronal and epithelial cells (Eisenhut and Wallace, 2011). The increased levels of extracellular ROS following stress, such as smoke exposure, leads to a 2.5 -fold increase in $\mathrm{Ca}^{2+}$ influx following TRPA1 activation in human bronchial epithelial cells (Lin et al., 2015). This contributes to increased intracellular ROS (via NADPH oxidase) activating the MAPK pathway and increasing the secretion of IL-8 in innate immune cells (Figure 3A) (Lin et al., 2015). The relationship between altered chloride channels and airway-related inflammation was recently reviewed (Sala-Rabanal et al., 2015) and also included the chloride channel regulator, the calcium-activated chloride channel (TMEM16A), and chloride exchangers (SLC26A4 and SLC26A9), as potential regulators of inflammation.

Additionally, ion channels have been shown to be involved in the development of senescence. For example, expression of the sodium voltage-gated channel SCN9A maintains cellular senescence induced by oncogene expression, whereas loss of this channel allows mammary epithelial cells to escape senescence development (Warnier et al., 2018). SCN9A is upregulated in an NF- $\mathrm{B}$-dependent manner following oncogene induced senescence, and induces plasma membrane depolarisation in a manner similar to that of calcium and potassium ion channels (Wiel et al., 2014; Warnier et al., 2018). TRP channel, TRPC5, has also been implicated in the development of senescence in mouse vascular endothelial cells in a ROS-dependent manner, with $\beta$-galactosidase staining reduced in cells lacking this gene (Li Z. et al., 2017). Therefore, therapeutics targeting ion channels could be useful in restoring endothelial cell function and reducing the incidence of cardiac disease in this context (Minamino et al., 2002). In contrast to the reversal of senescence, small molecule activation of $\mathrm{K}_{\mathrm{V}} 11.3$ plasma-membrane potassium channel have shown promise in inducing $\mathrm{p} 16^{\mathrm{INK} 4 \mathrm{~A}}$-dependent senescence in melanoma cells in vivo, where the induction of senescence is preferable (Perez-Neut et al., 2016). Induction of senescence involved an AMPK-dependent cellular stress response following a rapid increase in intracellular calcium as evidenced by increased rates of autophagy. Consequently, therapeutics designed to activate or reverse senescence could both be of use in the aging population.

\section{INTERVENTION STRATEGIES TO RESTORE MITOCHONDRIAL FUNCTION}

The removal of senescent cells is a strategy used to improve physical capacity in old age. The use of senolytics to clear senescent cells by exploiting their apoptotic pathways have already shown promise in pre-clinical studies alleviating the burden of SASP (Kirkland and Tchkonia, 2017). Particularly the SASP components IL- 6 , IL- $1 \alpha$ and TGF- $\beta$ show decreased expression with the use of senolytics in senescent murine hematopoietic stem cells, human lung fibroblasts and a murine model of pulmonary fibrosis (Chang et al., 2016; Schafer et al., 2017). Consequently, the removal of senescent cells should reduce the overall pro-inflammatory profile in older individuals. In senescent human fibroblasts the anti-aging drug resveratrol, has recently been shown to reduce SASP potentially through targeting mitochondrial dysfunction in a $\mathrm{p} 16^{\mathrm{INK} 4 \mathrm{~A}}$-dependent mechanism (Pitozzi et al., 2013; Kirkland and Tchkonia, 2017). The senolytic properties of resveratrol in senescent porcine aortic endothelial cells involve mitochondrial $\mathrm{Ca}^{2+}$ overload-induced apoptosis (Madreiter-Sokolowski et al., 2019). However, the difficulty resides in the specific targeting of senescent cells in humans, as expression of senescent hallmarks is highly variable in a tissue-specific manner, as well as in the potential detrimental effect of this removal (Hudgins et al., 2018). Considering aging as an adaptation, it can be difficult to conceive that removal of senescent cells will only have beneficial effects. This may vary from organ to organ and as of today it is difficult to predict the tissue-specific effects of senolytics without further testing. Other intervention strategies should now be considered.

Many interventions affecting mitochondrial function have been shown to affect lifespan and healthspan. Inducing mild 
mitochondrial stress throughout the life course may result in better outcomes later in life due to a programming effect, termed mitohormesis (Yun and Finkel, 2014). As the ROS theory of aging is so popular, anti-oxidants were one of the first drugs utilized to ameliorate mitochondrial dysfunction during aging (Cutler, 1984; Aversa et al., 2016). Whilst ROS have long since been believed to cause cellular dysfunction through the oxidative damage they cause, their role within the cell is much more complex. The generation of mitochondrial-targeted anti-oxidants have allowed the effects of anti-oxidants specifically on mitochondria and metabolism to be studied more effectively. These antioxidants have been shown to protect the mitochondria from further oxidative damage more effectively than natural anti-oxidants such as Vitamin E in rat liver mitochondria and human osteosarcoma cells, sustaining their function during oxidative stress (Smith et al., 1999). Whilst anti-oxidant supplementation can reduce oxidative stress, they can also have detrimental effects on health in the long term (Peternelj and Coombes, 2011; Desjardins et al., 2017). This is because ROS are essential for optimal cellular signaling, including that of ion channels. Anti-oxidants may not be beneficial as an intervention for restoring mitochondrial function as they may over-compensate, detrimentally affecting vital cellular functions and organism physiology. For example, anti-oxidants have been shown to affect ion channel activity and can block ATP-sensitive potassium channels in feline cerebral arterioles, inhibiting the action of hydrogen peroxide in vasodilation (Wei Enoch et al., 1998).

Metformin, used for the treatment of diabetes, has wide-ranging effects on mitochondrial function through multiple mechanisms (Viollet et al., 2012). These mechanisms include decreased gluconeogenesis and mitochondrial complex I inhibition resulting in partially inhibited metabolism (Viollet et al., 2012). This response increases the activation of AMPK as a response to metabolic stress. AMPK as the master regulator of metabolism has the ability to induce many beneficial changes within the mitochondria, from inducing mitochondrial biogenesis to employing autophagy to regain energy homeostasis (Hardie et al., 2012). This allows healthy mitochondria to proliferate, whilst damaged mitochondria are removed through autophagy and broken down. AMPK also engages oxidative phosphorylation which has been shown to promote longevity in some organisms (Hardie et al., 2012).

This may account for the recent call to repurpose drugs such as metformin for slowing down the appearance of age-associated diseases (by slowing the aging process itself). Contrary to recent data implicating AMPK-activation in promoting longevity, activation of AMPK has been shown to induce T cell senescence (Lanna et al., 2014), resulting in defective TCR signaling and reduced proliferation. Similarly, NK cell function has been found to be reduced in an AMPK-dependent manner in individuals aged 70 and over (Müller-Durovic et al., 2016). This may hinder the use of metformin as a potential healthspan extending drug in clinical trials. In terms of ion channels, polyspecific cation transporters such as OCT1 (SLC22A1) are required for accumulation of intracellular metformin and its interaction with mitochondria and endoplasmic reticulum
(Chien et al., 2015). This interaction has been observed in human embryonic kidney cells and mouse liver, where OCT1 deletion results in a similar action on metabolism as metformin by disrupting glycolysis and activating AMPK (Chen et al., 2014). Metformin has been shown to directly interact with the intracellular chloride channel (CLIC1) in some human cells (Gritti et al., 2014). In human glioblastoma stem cells inactivation of CLIC1 by metformin inhibits the chloride current and induces cell cycle arrest (Gritti et al., 2014). Metformin has been shown to have no effect on $\mathrm{Ca}^{2+}$ current amplitude and $\mathrm{K}^{+}$-contraction in smooth arterial muscle cells and therefore does not affect vasodilation or contraction in guinea-pig arterial SMCs (Nakamura et al., 1998). In adult rat myocytes, however, metformin has been shown to normalize aberrant intracellular $\mathrm{Ca}^{2+}$ clearing induced by high glucose (Ren et al., 1999). This finding may implicate metformin in increasing cardioprotection in diabetic patients.

Long-term caloric restriction has previously been shown to reduce oxidative mitochondrial DNA damage with age in rat liver and also decrease ROS production rate within the mitochondria (Lopez-Torres et al., 2002). Therefore, utilizing caloric restriction as a therapeutic strategy to combat aging has received wide-spread attention. Caloric restriction has long been shown to extend lifespan in a number of animal models ranging from monkeys to yeast, however, studying the effects in humans has been challenging due to ethical and methodological concerns (Heilbronn and Ravussin, 2003). From studies in rhesus and cynomolgus monkeys it has been shown that caloric restriction can extend healthspan by delaying the onset of age-related chronic diseases, such as cardiovascular disease and insulin insensitivity (Type II Diabetes) (Cefalu et al., 2004; Mattison et al., 2017). Cefalu and colleagues reported a twofold increased risk for age-related morbidities in control animals, extending from frailty through to diabetes and cancer compared to those on a calorie restricted diets in an examination of two different studies (Cefalu et al., 2004). Utilizing very low-calorie diets as a short-term alternative for studying the effects of caloric restriction, has shown that reducing caloric intake in humans brings about a series of beneficial health effects. The most striking finding is that an 8-week low-calorie diet can achieve remission of impaired insulin responses, which can be sustained for at least 6 months (Steven et al., 2016). Similar studies have also shown to reduce inflammatory and oxidative stress biomarkers (Merra et al., 2017) and improve cardiovascular health in humans (Wei et al., 2017). Although only short-term, these studies show that diets utilizing caloric restriction can benefit health and may represent a strategy for delaying age-related disease progression which can be used as both an intervention and a preventative strategy. Caloric restriction has been shown to activate AMPK-mTOR signaling inducing mitochondrial biogenesis, improved energy homeostasis and increased lifespan (Dong et al., 2017; Marin et al., 2017; Wierman et al., 2017). Additionally, caloric restriction has been shown to increase $\mathrm{Ca}^{2+}$ retention and buffering capacity in mouse liver and rat brain mitochondria, resulting in reduced ischaemiareperfusion damage and reduced excitotoxicity (Amigo et al., 2017; Menezes-Filho et al., 2017). 
The positive effects of exercise on increasing mitochondrial health and increasing healthspan have been known for some time. The global effects of physical exercise on the hallmarks of aging has been reviewed recently (Rebelo-Marques et al., 2018). Exercise training in male young and old mice has been shown to promote biogenesis of mitochondria and mitochondrial autophagy and suppress pro-inflammatory cytokine production by up to $49 \%$ (Zhang et al., 2018). A similar effect has also been in seen in humans, whereby a significant increase in anti-oxidant levels and activity were observed in old active but not old sedentary individuals after incremental exercise (Bouzid et al., 2018). In aged mice an augmented oxidative profile following a low-impact and accessible swimming regime has been shown to aid in recovery after myocardial infarction even at durations as short as $15 \mathrm{~min}$, by decreasing ROS production by $48 \%$ (Zhao et al., 2018). In murine studies, the beneficial effects of exercise on mitochondrial health appear to be dependent on the induction of PGC- $1 \alpha$ expression, however, this link has yet to be confirmed within human skeletal muscle (Halling et al., 2017). Two months of training in 70-year old individuals has revealed that mitochondrial $\mathrm{Ca}^{2+}$ uptake can also be improved by exercise by increasing calcium uniporter expression (Zampieri et al., 2016). Exercise intervention in the elderly has come under scrutiny in the past due to the limited effects on mortality (West and Jones, 2013), however, a more recent meta-analysis looking at exercise prescription has confirmed reduced cardiovascular mortality from 10.4 to $7.6 \%$ (Anderson et al., 2016). Additionally, exercise has been shown to have positive effects on cognitive aging (Conner et al., 2017). As the elderly often suffer from multiple diseases taking additional medication and altering diet is often unfavorable. In this respect exercise is different from the other interventions described in this section and can also have advantageous social benefits. In conclusion this suggests that regular exercise in elderly can have advantageous effects on healthy ageing, decreasing both the hallmarks of aging and development of age-related disease.

\section{PERSPECTIVES}

Mitochondria are an essential entity of cells. Ion channels are an essential regulator of mitochondrial functions. Knowing the role of mitochondria in cellular energy building and the consequences of its dysregulation, it becomes evident that a deeper understanding of ion channel biology should enable to

\section{REFERENCES}

Abou-Sleiman, P. M., Muqit, M. M. K., and Wood, N. W. (2006). Expanding insights of mitochondrial dysfunction in Parkinson's disease. Nat. Rev. Neurosci. 7, 207-219. doi: 10.1038/nrn1868

Akiyama, H., Barger, S., Barnum, S., Bradt, B., Bauer, J., Cole, G. M., et al. (2000). Inflammation and Alzheimer's disease. Neurobiol. Aging 21, 383-421. doi: 10. 1016/S0197-4580(00)00124-X

Alberdi, E., Sánchez-Gómez, M. V., Cavaliere, F., Pérez-Samartín, A., Zugaza, J. L., Trullas, R., et al. (2010). Amyloid $\beta$ oligomers induce Ca2+ dysregulation and neuronal death through activation of ionotropic glutamate receptors. Cell Calcium 47, 264-272. doi: 10.1016/j.ceca.2009.12.010 provide better supportive strategies in the context of aging. The family of ion channels described in this review are involved in several physiological systems and influence immune responses, neuronal signaling and cardiovascular functions which are all very essential systems. In view of extending healthspan one should then consider investigating at potential ion channel modulators to influence mitochondria in an aging organism. Indeed, ion channels are currently being validated as targets for therapeutic development and their precise role during regulated and unregulated cell death is being investigated (Kunzelmann, 2016; Douthwaite et al., 2017; Grandi and Dobrev, 2017). Recent meta-analyses have concluded that the use of calcium-channel blockers can reduce the risk of developing Parkinson's disease by up to 30\% (Lang et al., 2015), and blockers of Cav1.3 for treating Parkinson's by reducing mitochondrial impairment and neuroinflammation are currently in Phase III clinical trials (Swart and Hurley, 2016). While the clinical effects of such interventions may be observed in a long-term manner, the investigation of oxidative stress and inflamm-aging should enable to have closer outcomes to look at. Indeed, chronic inflammation has been associated with a myriad of diseases and aged individuals with the low inflammation were shown to be distant from the risk category for most age-related diseases.

\section{AUTHOR CONTRIBUTIONS}

AL conceived and coordinated the writing of the manuscript. MS, BY-L, BB-Z, SP, and AL contributed to writing of this manuscript. $\mathrm{MS}$ and AL prepared the figures.

\section{FUNDING}

MS and SP are funded by the A*STAR Research Attachment Programme (ARAP), the Vice Chancellor Scholarship and the Doctoral Training Award, University of Southampton. BY$\mathrm{L}$ is funded in part from the Ministry of High Education and Scientific Research (grant LR16ES05) and D4P1 National Federative Project. BB- $\mathrm{Z}$ is funded in part from the Ministry of High Education and Scientific Research (grant IPT16LR08) and PRF D4P1 National Federative Project. AL is funded by the Singapore Immunology Network and the Agency for Science, Technology and Research (JCO DP 1434m00115).

Alers, S., Loffler, A. S., Wesselborg, S., and Stork, B. (2012). Role of Ampk-mtorUlk1/2 in the regulation of autophagy: cross talk, shortcuts, and feedbacks. Mol. Cell Biol. 32, 2-11. doi: 10.1128/MCB.06159-11

Aliper, A., Jellen, L., Cortese, F., Artemov, A., Karpinsky-Semper, D., Moskalev, A., et al. (2017). Towards natural mimetics of metformin and rapamycin. Aging 9, 2245-2268. doi: 10.18632/aging.101319

Amaral, M. E. C., Ribeiro, R. A., Vanzela, E. C., and Barbosa-Sampaio, H. C. (2016). Reduced Ampk $\alpha 2$ protein expression restores glucose-induced insulin secretion in islets from calorie-restricted rats. Int. J. Exp. Pathol. 97, 50-55. doi: 10.1111/iep.12165

Amigo, I., Menezes-Filho, S. L., Luévano-Martínez, L. A., Chausse, B., and Kowaltowski, A. J. (2017). Caloric restriction increases brain mitochondrial 
calcium retention capacity and protects against excitotoxicity. Aging Cell 16, 73-81. doi: 10.1111/acel.12527

Anderson, L., Oldridge, N., Thompson, D. R., Zwisler, A.-D., Rees, K., Martin, N., et al. (2016). Exercise-based cardiac rehabilitation for coronary heart disease. Cochrane Syst. Rev. Meta Anal. 67, 1-12. doi: 10.1016/j.jacc.2015. 10.044

Attali, B., Romey, G., Honore, E., Schmid-Alliana, A., Mattei, M. G., Lesage, F., et al. (1992). Cloning, functional expression, and regulation of two K+ channels in human $\mathrm{T}$ lymphocytes. J. Biol. Chem. 267, 8650-8657.

Aversa, R., Petrescu, R. V., Apicella, A., and Petrescu, F. I. (2016). One can slow down the aging through antioxidants. Am. J. Eng. Appl. Sci. 9:15. doi: 10.3844/ ajeassp.2016.1112.1126

Baar, M. P., Brandt, R. M. C., Putavet, D. A., Klein, J. D. D., Derks, K. W. J., Bourgeois, B. R. M., et al. (2017). Targeted apoptosis of senescent cells restores tissue homeostasis in response to chemotoxicity and aging. Cell 169, 132147.e16. doi: 10.1016/j.cell.2017.02.031

Baez-Franceschi, D., and Morley, J. E. (1999). Physiopathology of the Catabolism Associated with Malnutrition in the Elderly. Malnutrition in the Elderly. Berlin: Springer.

Bailey, K. L., Smith, L. M., Heires, A. J., Katafiasz, D. M., Romberger, D. J., and Levan, T. D. (2018). Aging leads to dysfunctional innate immune responses to Tlr2 and Tlr4 agonists. Aging Clin. Exp. Res. doi: 10.1007/s40520-018-1064-0 [Epub ahead of print]. doi: 10.1007/s40520-018-1064-0

Baker, D. J., Childs, B. G., Durik, M., Wijers, M. E., Sieben, C. J., Zhong, J., et al. (2016). Naturally occurring p16Ink4a-positive cells shorten healthy lifespan. Nature 530, 184-189. doi: 10.1038/nature16932

Baker, D. J., Wijshake, T., Tchkonia, T., LeBrasseur, N. K., Childs, B. G., van de Sluis, B., et al. (2011). Clearance of p16 $6^{\text {Ink4a }}$-positive senescent cells delays ageing-associated disorders. Nature 479, 232-236. doi: 10.1038/nature10600

Banks, W. A., Farr, S. A., La Scola, M. E., and Morley, J. E. (2001). Intravenous human interleukin-1alpha impairs memory processing in mice: dependence on blood-brain barrier transport into posterior division of the septum. J. Pharmacol. Exp. Ther. 299, 536-541.

Banks, W. A., and Morley, J. E. (2003). Memories are made of this: recent advances in understanding cognitive impairments and dementia. J. Gerontol. A Biol. Sci. Med. Sci. 58, 314-321. doi: 10.1093/gerona/58.4.M314

Barber, R. C., Edwards, M. I., Xiao, G., Huebinger, R. M., Diaz-Arrastia, R., Wilhelmsen, K. C., et al. (2012). Serum granulocyte colony-stimulating factor and Alzheimer's disease. Dement. Geriatr. Cogn. Dis. Extra 2, 353-360. doi: $10.1159 / 000341780$

Barfod, E. T., Moore, A. L., and Lidofsky, S. D. (2001). Cloning and functional expression of a liver isoform of the small conductance $\mathrm{Ca} 2+$-activated $\mathrm{K}+$ channel Sk3. Am. J. Physiol. Cell Physiol. 280, C836-C842. doi: 10.1152/ajpcell. 2001.280.4.C836

Barrientos, A., Casademont, J., Rötig, A., Miró, Ò, Urbano-Márquez, Á, Rustin, P., et al. (1996). Absence of relationship between the level of electron transport chain activities and aging in human skeletal muscle. Biochem. Biophys. Res. Commun. 229, 536-539. doi: 10.1006/bbrc.1996.1839

Baumann, L., Gerstner, A., Zong, X., Biel, M., and Wahl-Schott, C. (2004). Functional characterization of the L-type Ca2+ channel Cav1.4alpha1 from mouse retina. Invest Ophthalmol. Vis. Sci. 45, 708-713. doi: 10.1167/iovs.030937

Bautista, D. M., Jordt, S. E., Nikai, T., Tsuruda, P. R., Read, A. J., Poblete, J., et al. (2006). Trpal mediates the inflammatory actions of environmental irritants and proalgesic agents. Cell 124, 1269-1282. doi: 10.1016/j.cell.2006. 02.023

Bayliss, J. A., Lemus, M. B., Stark, R., Santos, V. V., Thompson, A., Rees, D. J., et al. (2016). Ghrelin-Ampk signaling mediates the neuroprotective effects of calorie restriction in Parkinson's disease. J. Neurosci. 36, 3049-3063. doi: 10. 1523/JNEUROSCI.4373-15.2016

Belhadj Slimen, I., Najar, T., Ghram, A., Dabbebi, H., Ben Mrad, M., and Abdrabbah, M. (2014). Reactive oxygen species, heat stress and oxidativeinduced mitochondrial damage. A review. Int. J. Hyperthermia 30, 513-523. doi: 10.3109/02656736.2014.971446

Belsky, D. W., Caspi, A., Houts, R., Cohen, H. J., Corcoran, D. L., Danese, A., et al. (2015). Quantification of biological aging in young adults. Proc. Natl. Acad. Sci. U.S.A. 112, E4104-E4110. doi: 10.1073/pnas.1506264112
Belsky, D. W., Moffitt, T. E., Cohen, A. A., Corcoran, D. L., Levine, M. E., Prinz, J. A., et al. (2018). Eleven telomere, epigenetic clock, and biomarker-composite quantifications of biological aging: do they measure the same thing? Am. J. Epidemiol. 187, 1220-1230.

Bhattacharya, A., and Biber, K. (2016). The microglial ATP-gated ion channel P2X7 as a CNS drug target. Glia 64, 1772-1787. doi: 10.1002/glia.23001

Blalock, E. M., Chen, K.-C., Sharrow, K., Herman, J. P., Porter, N. M., Foster, T. C., et al. (2003). Gene microarrays in hippocampal aging: statistical profiling identifies novel processes correlated with cognitive impairment. J. Neurosci. 23, 3807-3819. doi: 10.1523/JNEUROSCI.23-09-03807.2003

Bose, T., Cieślar-Pobuda, A., and Wiechec, E. (2016). Role of ion channels in regulating $\mathrm{Ca} 2+$ homeostasis during the interplay between immune and cancer cells. Cell Death Dis. 6:e1648. doi: 10.1038/cddis.2015.23

Boss, G. R., and Seegmiller, J. E. (1981). Age-related physiological changes and their clinical significance. West. J. Med. 135, 434-440.

Bouzid, M. A., Filaire, E., Matran, R., Robin, S., and Fabre, C. (2018). Lifelong voluntary exercise modulates age-related changes in oxidative stress. Int. J. Sports Med. 39, 21-28. doi: 10.1055/s-0043-119882

Bruunsgaard, H., Andersen-Ranberg, K., Jeune, B., Pedersen, A. N., Skinhoj, P., and Pedersen, B. K. (1999). A high plasma concentration of TNF-alpha is associated with dementia in centenarians. J. Gerontol. A Biol. Sci. Med. Sci. 54, M357-M364. doi: 10.1093/gerona/54.7.M357

Bussian, T. J., Aziz, A., Meyer, C. F., Swenson, B. L., Van Deursen, J. M., and Baker, D. J. (2018). Clearance of senescent glial cells prevents tau-dependent pathology and cognitive decline. Nature 562, 578-582. doi: 10.1038/s41586-018-0543-y

Cefalu, W. T., Wang, Z. Q., Bell-Farrow, A. D., Collins, J., Morgan, T., and Wagner, J. D. (2004). Caloric restriction and cardiovascular aging in cynomolgus monkeys (Macaca fascicularis): metabolic, physiologic, and atherosclerotic measures from a 4-year intervention trial. J. Gerontol. A Biol. Sci. Med. Sci. 59, 1007-1014. doi: 10.1093/gerona/59.10.B1007

Cesari, M., Penninx, B. W., Newman, A. B., Kritchevsky, S. B., Nicklas, B. J., SuttonTyrrell, K., et al. (2003). Inflammatory markers and onset of cardiovascular events: results from the Health Abc study. Circulation 108, 2317-2322. doi: 10.1161/01.CIR.0000097109.90783.FC

Cesari, M., Penninx, B. W., Pahor, M., Lauretani, F., Corsi, A. M., Rhys Williams, G., et al. (2004). Inflammatory markers and physical performance in older persons: the Inchianti study. J. Gerontol. A Biol. Sci. Med. Sci. 59, 242-248. doi: 10.1093/gerona/59.3.M242

Cha, M.-Y., Kim, D. K., and Mook-Jung, I. (2015). The role of mitochondrial DNA mutation on neurodegenerative diseases. Exp. Mol. Med. 47:e150. doi: $10.1038 / \mathrm{emm} .2014 .122$

Chandel, N. S. (2015). Evolution of mitochondria as signaling organelles. Cell Metabol. 22, 204-206. doi: 10.1016/j.cmet.2015.05.013

Chang, J., Wang, Y., Shao, L., Laberge, R.-M., Demaria, M., Campisi, J., et al. (2016). Clearance of senescent cells by ABT263 rejuvenates aged hematopoietic stem cells in mice. Nat. Med. 22, 78. doi: 10.1038/nm.4010

Charolidi, N., Schilling, T., and Eder, C. (2015). Microglial Kv1.3 Channels and P2Y12 receptors differentially regulate cytokine and chemokine release from brain slices of young adult and aged mice. PLoS One 10:e0128463. doi: 10.1371/ journal.pone. 0128463

Charpentier, M., Sun, J., Martins, T. V., Radhakrishnan, G. V., Findlay, K., Soumpourou, E., et al. (2016). Nuclear-localized cyclic nucleotide-gated channels mediate symbiotic calcium oscillations. Science 352, 1102-1105. doi: 10.1126/science.aae0109

Chason, K. D., Jaspers, I., Parker, J., Sellers, S., Brighton, L. E., Hunsucker, S. A., et al. (2018). Age-associated changes in the respiratory epithelial response to influenza infection. J. Gerontol. A 73, 1643-1650. doi: 10.1093/gerona/gly126

Chen, L., Shu, Y., Liang, X., Chen, E. C., Yee, S. W., Zur, A. A., et al. (2014). Octl is a high-capacity thiamine transporter that regulates hepatic steatosis and is a target of metformin. Proc. Natl. Acad. Sci. U.S.A. 111, 9983-9988. doi: $10.1073 /$ pnas. 1314939111

Chiang, M.-C., Cheng, Y.-C., Chen, S.-J., Yen, C.-H., and Huang, R.-N. (2016). Metformin activation of ampk-dependent pathways is neuroprotective in human neural stem cells against Amyloid-beta-induced mitochondrial dysfunction. Exp. Cell Res. 347, 322-331. doi: 10.1016/j.yexcr.2016. 08.013

Chien, H.-C., Zur, A. A., Maurer, T. S., Yee, S.-W., Tolsma, J., Jasper, P., et al. (2015). Rapid method to determine intracellular drug concentrations in cellular uptake 
assays: application to metformin in Oct1-transfected Hek Cells. Drug Metab. Dispos. 44, 356-364. doi: 10.1124/dmd.115.066647

Chien, Y., Scuoppo, C., Wang, X., Fang, X., Balgley, B., Bolden, J. E., et al. (2011). Control of the senescence-associated secretory phenotype by nfkappaB promotes senescence and enhances chemosensitivity. Genes Dev. 25, 2125-2136. doi: 10.1101/gad.17276711

Childs, B. G., Durik, M., Baker, D. J., and van Deursen, J. M. (2015). Cellular senescence in aging and age-related disease: from mechanisms to therapy. Nat. Med. 21, 1424-1435. doi: 10.1038/nm.4000

Childs, B. G., Li, H., and Van Deursen, J. M. (2018). Senescent cells: a therapeutic target for cardiovascular disease. J. Clin. Invest. 128, 1217-1228. doi: 10.1172/ JCI95146

Chistiakov, D. A., Sobenin, I. A., Revin, V. V., Orekhov, A. N., and Bobryshev, Y. V. (2014). Mitochondrial aging and age-related dysfunction of mitochondria. BioMed. Res. Int. 2014:238463 doi: 10.1155/2014/238463

Chougnet, C. A., Thacker, R. I., Shehata, H. M., Hennies, C. M., Lehn, M. A., Lages, C. S., et al. (2015). Loss of phagocytic and antigen cross-presenting capacity in aging dendritic cells is associated with mitochondrial dysfunction. J. Immunol. 195, 2624-2632 doi: 10.4049/jimmunol.1501006

Climent, B., Sánchez, A., Moreno, L., Pérez-Vizcaíno, F., García-Sacristán, A., Rivera, L., et al. (2017). Underlying mechanisms preserving coronary basal tone and No-mediated relaxation in obesity: involvement of $\beta 1$ subunit-mediated upregulation of Bkca channels. Atherosclerosis 263, 227-236. doi: 10.1016/j. atherosclerosis.2017.06.354

Colombini, M. (2004). Vdac: the channel at the interface between mitochondria and the cytosol. Mol. Cell. Biochem. 256, 107-115. doi: 10.1023/B:MCBI. $0000009862.17396 .8 \mathrm{~d}$

Conner, K., Sweeney, C. Y., Brown, T., Childs, L., Rogers, S., and Gregory, T. (2017). Practical applications of physical activity for successful cognitive aging. JAAPA 30, 30-35. doi: 10.1097/01.JAA.0000520537.00581.f1

Connors, L. H., Sam, F., Skinner, M., Salinaro, F., Sun, F., Ruberg, F. L., et al. (2015). Heart failure due to age-related cardiac amyloid disease associated with wildtype transthyretin: a prospective, observational cohort study. Circulation 133, 282-290 doi: 10.1161/CIRCULATIONAHA.115.018852

Cutler, R. G. (1984). Antioxidants, aging and longevity. Free Radic. Biol. 6, 371-428. doi: 10.1016/B978-0-12-566506-3.50019-4

Dai, D.-F., Chiao, Y. A., Marcinek, D. J., Szeto, H. H., and Rabinovitch, P. S. (2014). Mitochondrial oxidative stress in aging and healthspan. Longev. Healthspan 3:6. doi: 10.1186/2046-2395-3-6

DeCoursey, T., Chandy, K., Gupta, S., and Cahalan, M. (1985). Voltage-dependent ion channels in T-lymphocytes. J. Neuroimmunol. 10, 71-95. doi: 10.1016/01655728(85)90035-9

del Valle, L. G. (2011). Oxidative stress in aging: theoretical outcomes and clinical evidences in humans. Biomed. Aging Pathol. 1, 1-7. doi: 10.1016/j.biomag.2011. 03.001

Demuro, A., Smith, M., and Parker, I. (2011). Single-channel Ca2+ imaging implicates A $\beta 1-42$ amyloid pores in Alzheimer's disease pathology. J. Cell Biol. 195, 515-524. doi: 10.1083/jcb.201104133

Desjardins, D., Cacho-Valadez, B., Liu, J. L., Wang, Y., Yee, C., Bernard, K., et al. (2017). Antioxidants reveal an inverted U-shaped dose-response relationship between reactive oxygen species levels and the rate of aging in Caenorhabditis elegans. Aging Cell 16, 104-112. doi: 10.1111/acel.12528

Di Benedetto, S., Muller, L., Wenger, E., Duzel, S., and Pawelec, G. (2017). Contribution of neuroinflammation and immunity to brain aging and the mitigating effects of physical and cognitive interventions. Neurosci. Biobehav. Rev. 75, 114-128. doi: 10.1016/j.neubiorev.2017.01.044

Diebold, L., and Chandel, N. S. (2016). Mitochondrial ros regulation of proliferating cells. Free Radic. Biol. Med. 100, 86-93. doi: 10.1016/j. freeradbiomed.2016.04.198

Dong, D., Cai, G.-Y., Ning, Y.-C., Wang, J.-C., Lv, Y., Hong, Q., et al. (2017). Alleviation of senescence and epithelial-mesenchymal transition in aging kidney by short-term caloric restriction and caloric restriction mimetics via modulation of Ampk/mtor signaling. Oncotarget 8, 16109-16121. doi: 10. 18632/oncotarget.14884

Doria, E., Buonocore, D., Focarelli, A., and Marzatico, F. (2012). Relationship between human aging muscle and oxidative system pathway. Oxid. Med. Cell. Longev. 2012:830257 doi: 10.1155/2012/830257
Douthwaite, J. A., Finch, D. K., Mustelin, T., and Wilkinson, T. C. (2017). Development of therapeutic antibodies to $\mathrm{G}$ protein-coupled receptors and ion channels: opportunities, challenges and their therapeutic potential in respiratory diseases. Pharmacol. Ther. 169, 113-123. doi: 10.1016/j.pharmthera. 2016.04.013

Doyle, D. A., Morais Cabral, J., Pfuetzner, R. A., Kuo, A., Gulbis, J. M., Cohen, S. L., et al. (1998). The structure of the potassium channel: molecular basis of K+ conduction and selectivity. Science 280, 69-77. doi: 10.1126/science.280.5360.69

Dutzler, R., Campbell, E. B., Cadene, M., Chait, B. T., and Mackinnon, R. (2002). $\mathrm{X}$-ray structure of a ClC chloride channel at $3.0 \mathrm{~A}$ reveals the molecular basis of anion selectivity. Nature 415, 287-294. doi: 10.1038/415287a

Eil, R., Vodnala, S. K., Clever, D., Klebanoff, C. A., Sukumar, M., Pan, J. H., et al. (2016). Ionic immune suppression within the tumour microenvironment limits T cell effector function. Nature 537, 539-543. doi: 10.1038/nature19364

Eisenhut, M., and Wallace, H. (2011). Ion channels in inflammation. Pflügers Arch. Eur. J. Physiol. 461, 401-421. doi: 10.1007/s00424-010-0917-y

Engelhart, M. J., Geerlings, M. I., Meijer, J., Kiliaan, A., Ruitenberg, A., Van Swieten, J. C., et al. (2004). Inflammatory proteins in plasma and the risk of dementia: the rotterdam study. Arch. Neurol. 61, 668-672. doi: 10.1001/archneur.61. 5.668

Fayet, G., Jansson, M., Sternberg, D., Moslemi, A.-R., Blondy, P., Lombès, A., et al. (2002). Ageing muscle: clonal expansions of mitochondrial DNA point mutations and deletions cause focal impairment of mitochondrial function. Neuromuscul. Disord. 12, 484-493. doi: 10.1016/S0960-8966(01) 00332-7

Feng, Z., Hanson, R. W., Berger, N. A., and Trubitsyn, A. (2016). Reprogramming of energy metabolism as a driver of aging. Oncotarget 7, 15410-15420. doi: 10.18632/oncotarget.7645

Ferguson, M., Mockett, R. J., Shen, Y., Orr, W. C., and Sohal, R. S. (2005). Age-associated decline in mitochondrial respiration and electron transport in Drosophila melanogaster. Biochem. J. 390, 501-511. doi: 10.1042/BJ20042130

Feske, S., Wulff, H., and Skolnik, E. Y. (2015). Ion channels in innate and adaptive immunity. Annu. Rev. Immunol. 33, 291-353. doi: 10.1146/annurev-immunol032414-112212

Forcina, L., Miano, C., and Musarò, A. (2018). The physiopathologic interplay between stem cells and tissue niche in muscle regeneration and the role of il6 on muscle homeostasis and diseases. Cytokine Growth Factor Rev. 41, 1-9. doi: 10.1016/j.cytogfr.2018.05.001

Franceschi, C. (2007). Inflammaging as a major characteristic of old people: can it be prevented or cured? Nutr. Rev. 65, S173-S176. doi: 10.1301/nr.2007.dec. S173-S176

Franceschi, C., Garagnani, P., Parini, P., Giuliani, C., and Santoro, A. (2018). Inflammaging: a new immune-metabolic viewpoint for age-related diseases. Nat. Rev. Endocrinol. 14, 576-590. doi: 10.1038/s41574-018-0059-4

Frasca, D., Diaz, A., Romero, M., and Blomberg, B. B. (2016). The generation of memory B cells is maintained, but the antibody response is not, in the elderly after repeated influenza immunizations. Vaccine 34, 2834-2840. doi: 10.1016/j. vaccine.2016.04.023

Frazier, H. N., Maimaiti, S., Anderson, K. L., Brewer, L. D., Gant, J. C., Porter, N. M., et al. (2017). Calcium's role as nuanced modulator of cellular physiology in the brain. Biochem. Biophys. Res. Commun. 483, 981-987. doi: 10.1016/j.bbrc.2016. 08.105

Ganesh, A., Al-Murshedi, F., Al-Zuhaibi, S., and Al-Thihli, K. (2017). Ocular Manifestations of Inborn Errors of Metabolism. The Eye in Pediatric Systemic Disease. Berlin: Springer.

Garcia-Calvo, M., Leonard, R. J., Novick, J., Stevens, S. P., Schmalhofer, W., Kaczorowski, G. J., et al. (1993). Purification, characterization, and biosynthesis of margatoxin, a component of Centruroides margaritatus venom that selectively inhibits voltage-dependent potassium channels. J. Biol. Chem. 268, 18866-18874.

García-Prieto, C., Pulido-Olmo, H., Ruiz-Hurtado, G., Gil-Ortega, M., Aranguez, I., Rubio, M., et al. (2015). Mild caloric restriction reduces blood pressure and activates endothelial ampk-pi3k-akt-enos pathway in obese Zucker rats. Vascul. Pharmacol. 65, 3-12. doi: 10.1016/j.vph.2014. 12.001

Ginaldi, L., Di Benedetto, M. C., and De Martinis, M. (2005). Osteoporosis, inflammation and ageing. Immun. Ageing 2:14. doi: 10.1186/1742-4933-2-14 
Gouspillou, G., Bourdel-Marchasson, I., Rouland, R., Calmettes, G., Biran, M., Deschodt-Arsac, V., et al. (2014). Mitochondrial energetics is impaired in vivo in aged skeletal muscle. Aging Cell 13, 39-48. doi: 10.1111/acel.12147

Grandi, E., and Dobrev, D. (2017). Non-ion channel therapeutics for heart failure and atrial fibrillation: Are Camkii inhibitors ready for clinical use? J. Mol. Cell Cardiol. 121, 300-303. doi: 10.1016/j.yjmcc.2017.10.010

Grimm, A., and Eckert, A. (2017). Brain aging and neurodegeneration: from a mitochondrial point of view. J. Neurochem. 143, 418-431. doi: 10.1111/jnc. 14037

Grissmer, S., Nguyen, A. N., Aiyar, J., Hanson, D. C., Mather, R. J., Gutman, G. A., et al. (1994). Pharmacological characterization of five cloned voltage-gated K+ channels, types Kv1.1, 1.2, 1.3, 1.5, and 3.1, stably expressed in mammalian cell lines. Mol. Pharmacol. 45, 1227-1234.

Gritti, M., Würth, R., Angelini, M., Barbieri, F., Peretti, M., Pizzi, E., et al. (2014). Metformin repositioning as antitumoral agent: selective antiproliferative effects in human glioblastoma stem cells, via inhibition of clic1-mediated ion current. Oncotarget 5, 11252-11268. doi: 10.18632/oncotarget.2617

Gross, A. M., Jaeger, Philipp, A., Kreisberg, Jason, F., Licon, K., et al. (2016). Methylome-wide analysis of chronic hiv infection reveals five-year increase in biological age and epigenetic targeting of HLA. Mol. Cell 62, 157-168. doi: 10.1016/j.molcel.2016.03.019

Guo, H., Callaway, J. B., and Ting, J. P. (2015). Inflammasomes: mechanism of action, role in disease, and therapeutics. Nat. Med. 21, 677-687. doi: 10.1038/ nm.3893

Haddad, F., Zaldivar, F., Cooper, D. M., and Adams, G. R. (2005). il-6-induced skeletal muscle atrophy. Journal of Applied Physiology 98, 911-917. doi: 10.1152/ japplphysiol.01026.2004

Hafner-Bratkovic, I., and Pelegrin, P. (2018). Ion homeostasis and ion channels in Nlrp3 inflammasome activation and regulation. Curr. Opin. Immunol. 52, 8-17. doi: 10.1016/j.coi.2018.03.010

Hagen, T. M., Yowe, D. L., Bartholomew, J. C., Wehr, C. M., Do, K. L., Park, J. Y., et al. (1997). Mitochondrial decay in hepatocytes from old rats: membrane potential declines, heterogeneity and oxidants increase. Proc. Natl. Acad. Sci. U.S.A. 94, 3064-3069. doi: 10.1073/pnas.94.7.3064

Hak, A. E., Pols, H. A., Van Hemert, A. M., Hofman, A., and Witteman, J. C. (2000). Progression of aortic calcification is associated with metacarpal bone loss during menopause: a population-based longitudinal study. Arterioscler. Thromb. Vasc. Biol. 20, 1926-1931. doi: 10.1161/01.ATV.20.8.1926

Halling, J. F., Ringholm, S., Olesen, J., Prats, C., and Pilegaard, H. (2017). Exercise training protects against aging-induced mitochondrial fragmentation in mouse skeletal muscle in a PGC-1 $\alpha$ dependent manner. Exp. Gerontol. 96, 1-6. doi: 10.1016/j.exger.2017.05.020

Han, Y., Shi, Y., Han, Z., Sun, L., and Fan, D. (2007). Detection of potassium currents and regulation of multidrug resistance by potassium channels in human gastric cancer cells. Cell Biol. Int. 31, 741-747. doi: 10.1016/j.cellbi.2007. 01.008

Hannum, G., Guinney, J., Zhao, L., Zhang, L., Hughes, G., Sadda, S., et al. (2013). Genome-wide methylation profiles reveal quantitative views of human aging rates. Mol. Cell 49, 359-367. doi: 10.1016/j.molcel.2012.10.016

Hansson, G. K. (2005). Inflammation, atherosclerosis, and coronary artery disease. New Engl. J. Med. 352, 1685-1695. doi: 10.1056/NEJMra0 43430

Hardie, D. G., Ross, F. A., and Hawley, S. A. (2012). Ampk: a nutrient and energy sensor that maintains energy homeostasis. Nat. Rev. Mol. Cell Biol. 13, 251-262. doi: $10.1038 / \mathrm{nrm} 3311$

Harman, D. (1992). Free radical theory of aging. Mutat. Res. 275, 257-266. doi: 10.1016/0921-8734(92)90030-S

Hayflick, L. (1994). How and why we age. New York, NY: Ballantine Books.

Hebert, A. S., Dittenhafer-Reed, K. E., Yu, W., Bailey, D. J., Selen, E. S., Boersma, M. D., et al. (2013). Calorie restriction and Sirt3 trigger global reprogramming of the mitochondrial protein acetylome. Mol. Cell 49, 186-199. doi: 10.1016/j. molcel.2012.10.024

Heilbronn, L. K., and Ravussin, E. (2003). Calorie restriction and aging: review of the literature and implications for studies in humans. Am. J. Clin. Nutr. 78, 361-369. doi: 10.1093/ajcn/78.3.361

Heinonen, S., Buzkova, J., Muniandy, M., Kaksonen, R., Ollikainen, M., Ismail, K., et al. (2015). Impaired mitochondrial biogenesis in adipose tissue in acquired obesity. Diabetes 64, 3135-3145. doi: 10.2337/db14-1937
Herbst, A., Wanagat, J., Cheema, N., Widjaja, K., Mckenzie, D., and Aiken, J. M. (2016). Latent mitochondrial DNA deletion mutations drive muscle fiber loss at old age. Aging Cell 15, 1132-1139. doi: 10.1111/acel.12520

Herpich, C., Ost, M., Franz, K., Otten, L., Coleman, V., Klaus, S., et al. (2018). Association of higher Il-6. Tnf-alpha and Ifn-gamma levels with health-related quality of life in older patients. Clin. Nutr. 37:S44. doi: 10.1016/j.clnu.2018.06. 1204

Herranz, N., Gallage, S., Mellone, M., Wuestefeld, T., Klotz, S., Hanley, C. J., et al. (2015). mtor regulates Mapkapk2 translation to control the senescenceassociated secretory phenotype. Nat. Cell Biol. 17, 1205-1217. doi: 10.1038/ ncb3225

Hisamoto, K., Ohmichi, M., Kurachi, H., Hayakawa, J., Kanda, Y., Nishio, Y., et al. (2001). Estrogen induces the Akt-dependent activation of endothelial nitricoxide synthase in vascular endothelial cells. J. Biol. Chem. 276, 3459-3467. doi: 10.1074/jbc.M005036200

Holmes, C., Cunningham, C., Zotova, E., Woolford, J., Dean, C., Kerr, S., et al. (2009). Systemic inflammation and disease progression in Alzheimer disease. Neurology 73, 768-774. doi: 10.1212/WNL.0b013e3181b6bb95

Hoppa, M. B., Gouzer, G., Armbruster, M., Ryan, and Timothy, A. (2014). Control and plasticity of the presynaptic action potential waveform at small CNS nerve terminals. Neuron 84, 778-789. doi: 10.1016/j.neuron.2014. 09.038

Horvath, S., Erhart, W., Brosch, M., Ammerpohl, O., Von Schönfels, W., Ahrens, M., et al. (2014). Obesity accelerates epigenetic aging of human liver. Proc. Natl. Acad. Sci. U.S.A. 111, 15538-15543. doi: 10.1073/pnas.141275 9111

Hou, Z.-S., Ulloa-Aguirre, A., and Tao, Y.-X. (2018). Pharmacoperone drugs: targeting misfolded proteins causing lysosomal storage-, ion channels-, and G protein-coupled receptors-associated conformational disorders. Exp. Rev. Clin. Pharmacol. 11, 611-624. doi: 10.1080/17512433.2018.1480367

Huang, J., Duong, M., Killian, K., Raina, P., Xie, Y., Dragoman, A., et al. (2018). Spirometry is a marker of general health and disability in the elderly: the canadian longitudinal study of aging. Am. J. Respir. Crit. Care Med. 197:A6391

Hudgins, A. D., Tazearslan, C., Tare, A., Zhu, Y., Huffman, D., and Suh, Y. (2018). Age- and tissue-specific expression of senescence biomarkers in mice. Front. Genet. 9:59. doi: 10.3389/fgene.2018.00059

Hugnot, J. P., Salinas, M., Lesage, F., Guillemare, E., De Weille, J., Heurteaux, C., et al. (1996). Kv8.1, a new neuronal potassium channel subunit with specific inhibitory properties towards Shab and Shaw channels. Embo J. 15, 3322-3331. doi: 10.1002/j.1460-2075.1996.tb00697.x

Jager, S., Handschin, C., St-Pierre, J., and Spiegelman, B. M. (2007). Amp-activated protein kinase (Ampk) action in skeletal muscle via direct phosphorylation of Pgc-1alpha. Proc. Natl. Acad. Sci. U.S.A. 104, 12017-12022. doi: 10.1073/pnas. 0705070104

Jahangir, A., Ozcan, C., Holmuhamedov, E. L., and Terzic, A. (2001). Increased calcium vulnerability of senescent cardiac mitochondria: protective role for a mitochondrial potassium channel opener. Mech. Ageing Dev. 122, 1073-1086. doi: 10.1016/S0047-6374(01)00242-1

Jo, E. K., Kim, J. K., Shin, D. M., and Sasakawa, C. (2016). Molecular mechanisms regulating Nlrp3 inflammasome activation. Cell Mol. Immunol. 13, 148-159. doi: $10.1038 / \mathrm{cmi} .2015 .95$

Jones, D. L., Rodriguez, V. J., Alcaide, M. L., Barylski, N., Cabral, D., Rundek, T., et al. (2017). Subclinical atherosclerosis among young and middle-aged adults using carotid intima-media thickness measurements. South. Med. J. 110, 733-737. doi: 10.14423/SMJ.0000000000000728

Jones, J. L., Peana, D., Veteto, A. B., Lambert, M. D., Nourian, Z., Karasseva, N. G., et al. (2018). Trpv4 increases cardiomyocyte calcium cycling and contractility yet contributes to damage in the aged heart following hypoosmotic stress. Cardiovasc. Res. 115, 46-56. doi: 10.1093/cvr/cvy156

Jørgensen, L., Engstad, T., and Jacobsen, B. K. (2001). Bone mineral density in acute stroke patients: low bone mineral density may predict first stroke in women. Stroke 32, 47-51. doi: 10.1161/01.STR.32.1.47

Jornayvaz, F. R., and Shulman, G. I. (2010). Regulation of mitochondrial biogenesis. Essays Biochem. 47, 69-84. doi: 10.1042/bse0470069

Jung, J. E., Kim, G. S., Chen, H., Maier, C. M., Narasimhan, P., Song, Y. S., et al. (2010). Reperfusion and neurovascular dysfunction in stroke: from basic mechanisms to potential strategies for neuroprotection. Mol. Neurobiol. 41, 172-179. doi: 10.1007/s12035-010-8102-z 
Kahn, S. (2003). The relative contributions of insulin resistance and beta-cell dysfunction to the pathophysiology of type 2 diabetes. Diabetologia 46, 3-19. doi: 10.1007/s00125-002-1009-0

Kalinkovich, A., and Livshits, G. (2017). Sarcopenic obesity or obese sarcopenia: a cross talk between age-associated adipose tissue and skeletal muscle inflammation as a main mechanism of the pathogenesis. Ageing Res. Rev. 35, 200-221. doi: 10.1016/j.arr.2016.09.008

Kamada, N., Kanaya, N., Hirata, N., Kimura, S., and Namiki, A. (2008). Cardioprotective effects of propofol in isolated ischemia-reperfused guinea pig hearts: role of K Atp channels and Gsk-3ß. Can. J. Anesthesia 55:595. doi: 10.1007/BF03021433

Kapetanovic, R., Bokil, N. J., and Sweet, M. J. (2015). Innate immune perturbations, accumulating DAMPs and inflammasome dysregulation: a ticking time bomb in ageing. Ageing Res. Rev. 24(Part A), 40-53. doi: 10.1016/j.arr.2015. 02.005

Kazlauskaite, A., and Muqit, M. M. (2015). Pink1 and Parkin-mitochondrial interplay between phosphorylation and ubiquitylation in Parkinson's disease. Febs J. 282, 215-223. doi: 10.1111/febs.13127

Khan, S. S., Singer, B. D., and Vaughan, D. E. (2017). Molecular and physiological manifestations and measurement of aging in humans. Aging Cell 16, 624-633. doi: $10.1111 /$ acel.12601

Kirkland, J. L., and Tchkonia, T. (2017). Cellular senescence: a translational perspective. Ebiomedicine 21, 21-28. doi: 10.1016/j.ebiom.2017.04.013

Kline, K. A., and Bowdish, D. M. E. (2016). Infection in an aging population. Curr. Opin. Microbiol. 29, 63-67. doi: 10.1016/j.mib.2015.11.003

Kollár, S., Berta, L., Vásárhelyi, Z. E., Balog, A., Vásárhelyi, B., Rigó, J. Jr., et al. (2015). Impact of aging on calcium influx and potassium channel characteristics of T lymphocytes. Oncotarget 6, 13750-13756. doi: 10.18632/oncotarget.3808

Kramer, I. F., Snijders, T., Smeets, J. S., Leenders, M., Van Kranenburg, J., Den Hoed, M., et al. (2017). Extensive type Ii muscle fiber atrophy in elderly female hip fracture patients. J. Gerontol. A Biomed. Sci. Med. Sci. 72, 1369-1375. doi: 10.1093/gerona/glw253

Kraytsberg, Y., Kudryavtseva, E., Mckee, A. C., Geula, C., Kowall, N. W., and Khrapko, K. (2006). Mitochondrial Dna deletions are abundant and cause functional impairment in aged human substantia nigra neurons. Nat. Genet. 38, 518-520. doi: 10.1038/ng1778

Krishnamurthy, J., Torrice, C., Ramsey, M. R., Kovalev, G. I., Al-Regaiey, K., Su, L., et al. (2004). Ink4a/Arf expression is a biomarker of aging. J. Clin. Invest. 114, 1299-1307. doi: 10.1172/JCI200422475

Krysko, D. V., Agostinis, P., Krysko, O., Garg, A. D., Bachert, C., Lambrecht, B. N., et al. (2011). Emerging role of damage-associated molecular patterns derived from mitochondria in inflammation. Trends Immunol. 32, 157-164. doi: 10.1016/j.it.2011.01.005

Kulbacka, J., Choromańska, A., Rossowska, J., Weżgowiec, J., Saczko, J., and Rols, M.-P. (2017). "Cell membrane transport mechanisms: ion channels and electrical properties of cell membranes," in Transport Across Natural and Modified Biological Membranes and its Implications in Physiology and Therapy. eds J. Kulbacka and S. Satkauskas (Cham: Springer International Publishing).

Kumar, P., Kumar, D., Jha, S. K., Jha, N. K., and Ambasta, R. K. (2016). Ion channels in neurological disorders. Adv. Protein Chem. Struct. Biol. 103, 97-136 doi: 10.1016/bs.apcsb.2015.10.006

Kunzelmann, K. (2016). Ion channels in regulated cell death. Cell. Mol. Life Sci. 73, 2387-2403. doi: 10.1007/s00018-016-2208-z

Labbadia, J., and Morimoto, R. I. (2015). The biology of proteostasis in aging and disease. Ann. Rev. Biochem. 84, 435-464. doi: 10.1146/annurev-biochem060614-033955

Lam, A., Karekar, P., Shah, K., Hariharan, G., Fleyshman, M., Kaur, H., et al. (2018). Drosophila voltage-gated calcium channel $\alpha 1$-subunits regulate cardiac function in the aging heart. Sci. Rep. 8:6910. doi: 10.1038/s41598-01825195-0

Lan, M., Shi, Y., Han, Z., Hao, Z., Pan, Y., Liu, N., et al. (2005). Expression of delayed rectifier potassium channels and their possible roles in proliferation of human gastric cancer cells. Cancer Biol. Ther. 4, 1342-1347. doi: 10.4161/cbt.4. 12.2175

Lang, Y., Gong, D., and Fan, Y. (2015). Calcium channel blocker use and risk of Parkinson's disease: a meta-analysis. Pharmacoepidemiol. Drug Safety 24, 559-566. doi: 10.1002/pds.3781
Lanna, A., Henson, S. M., Escors, D., and Akbar, A. N. (2014). The kinase p38 activated by the metabolic regulator Ampk and scaffold tab1 drives the senescence of human T cells. Nat. Immunol. 15, 965-972. doi: 10.1038/ni.2981

Latorre, R., Castillo, K., Carrasquel-Ursulaez, W., Sepulveda, R. V., GonzalezNilo, F., Gonzalez, C., et al. (2017). Molecular determinants of bk channel functional diversity and functioning. Physiol. Rev. 97, 39-87. doi: 10.1152/ physrev.00001.2016

Le Page, A., Dupuis, G., Larbi, A., Witkowski, J. M., and Fülöp, T. (2018). Signal transduction changes in $\mathrm{cd} 4+$ and $\mathrm{cd} 8+\mathrm{T}$ cell subpopulations with aging. Exp. Gerontol. 105, 128-139. doi: 10.1016/j.exger.2018.01.005

Lesnefsky, E. J., Moghaddas, S., Tandler, B., Kerner, J., and Hoppel, C. L. (2001). Mitochondrial Dysfunction in Cardiac Disease: Ischemia-Reperfusion. Aging, and Heart Failure. J. Mol. Cell. Cardiol. 33, 1065-1089. doi: 10.1006/jmcc.2001. 1378

Levine, B., Kalman, J., Mayer, L., Fillit, H. M., and Packer, M. (1990). Elevated circulating levels of tumor necrosis factor in severe chronic heart failure. N. Engl. J. Med. 323, 236-241. doi: 10.1056/NEJM19900726323 0405

Levitan, I. B., and Kaczmarek, L. K. (2015). The Neuron: Cell and Molecular Biology. Oxford: Oxford University Press. doi: 10.1093/med/9780199773893.001.0001

Lewis, R. J., Nielsen, K. J., Craik, D. J., Loughnan, M. L., Adams, D. A., Sharpe, I. A., et al. (2000). Novel omega-conotoxins from Conus catus discriminate among neuronal calcium channel subtypes. J. Biol. Chem. 275, 35335-35344. doi: $10.1074 /$ jbc.M002252200

Li, H., Shen, L., Hu, P., Huang, R., Cao, Y., Deng, J., et al. (2017). Aging-associated mitochondrial DNA mutations alter oxidative phosphorylation machinery and cause mitochondrial dysfunctions. Biochim. Biophys. Acta 1863, 2266-2273. doi: 10.1016/j.bbadis.2017.05.022

Li, Z., Guo, G., Wang, H., Si, X., Zhou, G., Xiong, Y., et al. (2017). Trpc5 channel modulates endothelial cells senescence. Eur. J. Pharmacol. 802, 27-35. doi: 10.1016/j.ejphar.2017.02.037

Licastro, F., Pedrini, S., Caputo, L., Annoni, G., Davis, L. J., Ferri, C., et al. (2000). Increased plasma levels of interleukin-1, interleukin-6 and alpha-1antichymotrypsin in patients with Alzheimer's disease: peripheral inflammation or signals from the brain? J. Neuroimmunol. 103, 97-102. doi: 10.1016/S01655728(99)00226-X

Lin, A. H., Liu, M. H., Ko, H. K., Perng, D. W., Lee, T. S., and Kou, Y. R. (2015). Lung epithelial trpal transduces the extracellular ros into transcriptional regulation of lung inflammation induced by cigarette smoke: the role of influxed $\mathrm{Ca}(2)(+)$. Med. Inflamm. 2015:148367. doi: 10.1155/2015/ 148367

Lin, J., Handschin, C., and Spiegelman, B. M. (2005). Metabolic control through the pgc-1 family of transcription coactivators. Cell Metab. 1, 361-370. doi: $10.1016 /$ j.cmet.2005.05.004

Lopez-Candales, A., Hernandez Burgos, P. M., Hernandez-Suarez, D. F., and Harris, D. (2017). Linking chronic inflammation with cardiovascular disease: from normal aging to the metabolic syndrome. J. Nat. Sci. 3:e341.

López-Lluch, G., Hunt, N., Jones, B., Zhu, M., Jamieson, H., Hilmer, S., et al. (2006). Calorie restriction induces mitochondrial biogenesis and bioenergetic efficiency. Proc. Natl. Acad. Sci. U.S.A. 103, 1768-1773. doi: 10.1073/pnas. 0510452103

López-Lluch, G., Irusta, P. M., Navas, P., and De Cabo, R. (2008). Mitochondrial biogenesis and healthy aging. Exp. Gerontol. 43, 813-819. doi: 10.1016/j.exger. 2008.06.014

López-Otín, C., Blasco, M. A., Partridge, L., Serrano, M., and Kroemer, G. (2013). The hallmarks of aging. Cell 153, 1194-1217. doi: 10.1016/j.cell.2013.05.039

Lopez-Torres, M., Gredilla, R., Sanz, A., and Barja, G. (2002). Influence of aging and long-term caloric restriction on oxygen radical generation and oxidative DNA damage in rat liver mitochondria. Free Radic. Biol. Med. 32, 882-889. doi: 10.1016/S0891-5849(02)00773-6

Lowsky, D. J., Olshansky, S. J., Bhattacharya, J., and Goldman, D. P. (2014). Heterogeneity in healthy aging. J. Gerontol. A 69, 640-649. doi: 10.1093/gerona/ glt162

Madeo, F., Carmona-Gutierrez, D., Kepp, O., and Kroemer, G. (2018). Spermidine delays aging in humans. Aging 10, 2209-2211. doi: 10.18632/aging.101517

Madreiter-Sokolowski, C. T., Waldeck-Weiermair, M., Bourguignon, M.-P., Villeneuve, N., Gottschalk, B., Klec, C., et al. (2019). Enhanced intercompartmental Ca2+ flux modulates mitochondrial metabolism and apoptotic 
threshold during aging. Redox Biol. 20, 458-466. doi: 10.1016/j.redox.2018. 11.003

Makielski, J. C., Limberis, J., Fan, Z., and Kyle, J. W. (1999). Intrinsic lidocaine affinity for Na channels expressed in Xenopus oocytes depends on alpha (hH1 vs. rSkM1) and beta 1 subunits. Cardiovasc. Res. 42, 503-509. doi: 10.1016/ S0008-6363(99)00024-3

Manolagas, S. C., and Jilka, R. L. (1995). Bone marrow, cytokines, and bone remodeling. Emerging insights into the pathophysiology of osteoporosis. N. Engl. J. Med. 332, 305-311. doi: 10.1056/NEJM199502023320506

Marijic, J., Li, Q., Song, M., Nishimaru, K., Stefani, E., and Toro, L. (2001). Decreased expression of voltage- and $\mathrm{Ca}(2+)$-activated $\mathrm{K}(+)$ channels in coronary smooth muscle during aging. Circ. Res. 88, 210-216. doi: 10.1161/01. RES.88.2.210

Marin, T. L., Gongol, B., Zhang, F., Martin, M., Johnson, D. A., Xiao, H., et al. (2017). Ampk promotes mitochondrial biogenesis and function by phosphorylating the epigenetic factors Dnmt1. Rbbp7, and Hat1. Sci. Signal. 10:eaaf7478. doi: 10.1126/scisignal.aaf7478

Marioni, R. E., Shah, S., Mcrae, A. F., Chen, B. H., Colicino, E., Harris, S. E., et al. (2015). DNA methylation age of blood predicts all-cause mortality in later life. Genome Biol. 16:25. doi: 10.1186/s13059-015-0584-6

Marselli, L., Suleiman, M., Masini, M., Campani, D., Bugliani, M., Syed, F., et al. (2014). Are we overestimating the loss of beta cells in type 2 diabetes? Diabetologia 57, 362-365. doi: 10.1007/s00125-013-3098-3

Martelli, S., Pender, S. L. F., and Larbi, A. (2016). Compartmentalization of immunosenescence: a deeper look at the mucosa. Biogerontology 17, 159-176. doi: 10.1007/s10522-015-9628-2

Matta, J. A., Cornett, P. M., Miyares, R. L., Abe, K., Sahibzada, N., and Ahern, G. P. (2008). General anesthetics activate a nociceptive ion channel to enhance pain and inflammation. Proc. Natl. Acad. Sci. U.S.A. 105, 8784-8789. doi: 10.1073/ pnas.0711038105

Mattison, J. A., Colman, R. J., Beasley, T. M., Allison, D. B., Kemnitz, J. W., Roth, G. S., et al. (2017). Caloric restriction improves health and survival of rhesus monkeys. Nat. Commun. 8:14063. doi: 10.1038/ncomms14063

Menezes-Filho, S. L., Amigo, I., Prado, F. M., Ferreira, N. C., Koike, M. K., Pinto, I. F. D., et al. (2017). Caloric restriction protects livers from ischemia/reperfusion damage by preventing $\mathrm{Ca} 2+$-induced mitochondrial permeability transition. Free Radic. Biol. Med. 110, 219-227. doi: 10.1016/j. freeradbiomed.2017.06.013

Merra, G., Gratteri, S., De Lorenzo, A., Barrucco, S., Perrone, M. A., Avolio, E., et al. (2017). Effects of very-low-calorie diet on body composition, metabolic state, and genes expression: a randomized double-blind placebo-controlled trial. Eur. Rev. Med. Pharmacol. Sci. 21, 329-345.

Metcalf, T. U., Wilkinson, P. A., Cameron, M. J., Ghneim, K., Chiang, C., Wertheimer, A. M., et al. (2017). Human monocyte subsets are transcriptionally and functionally altered in aging in response to pattern recognition receptor agonists. J. Immunol. 199, 1405-1417 doi: 10.4049/jimmunol.1700148

Miller, R. A. (1996). The aging immune system: primer and prospectus. Science 273, 70-74. doi: 10.1126/science.273.5271.70

Miller, R. R., Cappola, A. R., Shardell, M. D., Hawkes, W. G., Yu-Yahiro, J. A., Hebel, J. R., et al. (2006). Persistent changes in interleukin-6 and lower extremity function following hip fracture. J. Gerontol. A Biol. Sci. Med. Sci. 61, 1053-1058. doi: 10.1093/gerona/61.10.1053

Miller, R. R., Shardell, M. D., Hicks, G. E., Cappola, A. R., Hawkes, W. G., Yu-Yahiro, J. A., et al. (2008). Association between interleukin-6 and lower extremity function after hip fracture-the role of muscle mass and strength. J. Am. Geriatr. Soc. 56, 1050-1056. doi: 10.1111/j.1532-5415.2008.01708.x

Minamino, T., Miyauchi, H., Yoshida, T., Ishida, Y., Yoshida, H., and Komuro, I. (2002). Endothelial cell senescence in human atherosclerosis. Circulation 105, 1541-1544. doi: 10.1161/01.CIR.0000013836.85741.17

Mitchell, P. (1961). Coupling of phosphorylation to electron and hydrogen transfer by a chemi-osmotic type of mechanism. Nature 191, 144-148. doi: 10.1038/ $191144 \mathrm{a} 0$

Mitnitski, A. B. (2018). "Chapter 7 - epigenetic biomarkers for biological age," in Epigenetics of Aging and Longevity, eds A. Moskalev and A. M. Vaiserman (Boston: Academic Press).

Molony, R. D., Malawista, A., and Montgomery, R. R. (2018). Reduced dynamic range of antiviral innate immune responses in aging. Exp. Gerontol. 107, 130-135. doi: 10.1016/j.exger.2017.08.019
Molony, R. D., Nguyen, J. T., Kong, Y., Montgomery, R. R., Shaw, A. C., and Iwasaki, A. (2017). Aging impairs both primary and secondary RIG-I signaling for interferon induction in human monocytes. Sci. Signal. 10:eaan2392.

Montgomery, R. R., and Shaw, A. C. (2015). Paradoxical changes in innate immunity in aging: recent progress and new directions. J. Leukoc. Biol. 98, 937-943. doi: 10.1189/jlb.5MR0315-104R

Moore, A. H., Wu, M., Shaftel, S. S., Graham, K. A., and O’banion, M. K. (2009). Sustained expression of interleukin-1 $\beta$ in mouse hippocampus impairs spatial memory. Neuroscience 164, 1484-1495. doi: 10.1016/j.neuroscience.2009. 08.073

Morley, J. E., and Baumgartner, R. N. (2004). Cytokine-related aging process. J. Gerontol. A Biol. Sci. Med. Sci. 59, M924-M929. doi: 10.1093/gerona/59.9. M924

Mossmann, D., Vögtle, F.-N., Taskin, A. A., Teixeira, P. F., Ring, J., Burkhart, J. M., et al. (2014). Amyloid- $\beta$ peptide induces mitochondrial dysfunction by inhibition of preprotein maturation. Cell Metab. 20, 662-669. doi: 10.1016/j. cmet.2014.07.024

Müller-Durovic, B., Lanna, A., Polaco Covre, L., Mills, R. S., Henson, S. M., and Akbar, A. N. (2016). Killer cell lectin-like receptor g1 inhibits nk cell function through activation of adenosine $5^{\prime}$-monophosphate-activated protein kinase. J. Immunol. 197, 2891-2899 doi: 10.4049/jimmunol.1600590

Münzel, T., Gori, T., Keaney, J. F. Jr., Maack, C., and Daiber, A. (2015). Pathophysiological role of oxidative stress in systolic and diastolic heart failure and its therapeutic implications. Eur. Heart J. 36, 2555-2564. doi: 10.1093/ eurheartj/ehv305

Nagata, K., Duggan, A., Kumar, G., and Garcia-Anoveros, J. (2005). Nociceptor and hair cell transducer properties of Trpal, a channel for pain and hearing. J. Neurosci. 25, 4052-4061. doi: 10.1523/JNEUROSCI.0013-05.2005

Nakamura, T., and Lipton, S. A. (2017). Aberrant nitric oxide signaling contributes to protein misfolding in neurodegenerative diseases via s-nitrosylation and tyrosine nitration. Nitric Oxide 2017, 373-384. doi: 10.1016/B978-0-12804273-1.00027-2

Nakamura, Y., Ohya, Y., Onaka, U., Fujii, K., Abe, I., and Fujishima, M. (1998). Inhibitory action of insulin-sensitizing agents on calcium channels in smooth muscle cells from resistance arteries of guinea-pig. Br. J. Pharmacol. 123, 675-682. doi: 10.1038/sj.bjp.0701669

Navakkode, S., Liu, C., and Soong, T. W. (2018). Altered function of neuronal L-type calcium channels in ageing and neuroinflammation: implications in agerelated synaptic dysfunction and cognitive decline. Ageing Res. Rev. 42, 86-99. doi: 10.1016/j.arr.2018.01.001

Ng, T. P., Camous, X., Nyunt, M. S. Z., Vasudev, A., Tan, C. T. Y., Feng, L., et al. (2015). Markers of T-cell senescence and physical frailty: insights from Singapore longitudinal ageing studies. NPJ Aging Mech. Dis. 1:15005. doi: 10. 1038/npjamd.2015.5

Niccoli, T., and Partridge, L. (2012). Ageing as a risk factor for disease. Curr. Biol. 22, R741-R752. doi: 10.1016/j.cub.2012.07.024

Nicolle, L. E. (2016). Urinary tract infections in the older adult. Clin. Geriatr. Med. 32, 523-538. doi: 10.1016/j.cger.2016.03.002

Niedernhofer, L. J., and Robbins, P. D. (2018). Senotherapeutics for healthy ageing. Nat. Rev. Drug Discov. 17:377. doi: 10.1038/nrd.2018.44

Nikolich-Zugich, J. (2014). Aging of the T cell compartment in mice and humans: from no naive expectations to foggy memories. J. Immunol. 193, 2622-2629. doi: 10.4049/jimmunol.1401174

Núñez, L., Bird, G. S., Hernando-Pérez, E., Pérez-Riesgo, E., Putney, J. W. Jr., and Villalobos, C. (2018). Store-operated $\mathrm{Ca} 2+$ entry and $\mathrm{Ca} 2+$ responses to hypothalamic releasing hormones in anterior pituitary cells from Orail-/- and heptatrpc knockout mice. Biochim. Biophys. Acta Mol. Cell Res. doi: 10.1016/j. bbamcr.2018.11.006 [Epub ahead of print].

Oberwinkler, J., Lis, A., Giehl, K. M., Flockerzi, V., and Philipp, S. E. (2005). Alternative splicing switches the divalent cation selectivity of TRPM3 channels. J. Biol. Chem. 280, 22540-22548. doi: 10.1074/jbc.M5030 92200

O'Conor, C. J., Ramalingam, S., Zelenski, N. A., Benefield, H. C., Rigo, I., Little, D., et al. (2016). Cartilage-specific knockout of the mechanosensory ion channel TRPV4 decreases age-related osteoarthritis. Sci. Rep. 6:29053. doi: 10.1038/ srep29053

Oliveira, J. S., Redaelli, E., Zaharenko, A. J., Cassulini, R. R., Konno, K., Pimenta, D. C., et al. (2004). Binding specificity of sea anemone toxins to Nav 1.1-1.6 
sodium channels: unexpected contributions from differences in the Iv/S3-S4 outer loop. J. Biol. Chem. 279, 33323-33335. doi: 10.1074/jbc.M404344200

O’Rourke, B. (2007). Mitochondrial Ion channels. Annu. Rev. Physiol. 69, 19-49. doi: 10.1146/annurev.physiol.69.031905.163804

Pang, L., Ye, W., Che, X. M., Roessler, B. J., Betz, A. L., and Yang, G. Y. (2001). Reduction of inflammatory response in the mouse brain with adenoviralmediated transforming growth factor-ss1 expression. Stroke 32, 544-552. doi: 10.1161/01.STR.32.2.544

Pardo, L. A. (2004). Voltage-gated potassium channels in cell proliferation. Physiology 19, 285-292. doi: 10.1152/physiol.00011.2004

Pardo, L. A., Contreras-Jurado, C., Zientkowska, M., Alves, F., and Stühmer, W. (2005). Role of voltage-gated potassium channels in cancer. J. Membr. Biol. 205, 115-124. doi: 10.1007/s00232-005-0776-1

Parker, W. D. Jr., Boyson, S. J., and Parks, J. K. (1989). Abnormalities of the electron transport chain in idiopathic Parkinson's disease. Ann. Neurol. 26, 719-723. doi: $10.1002 /$ ana.410260606

Payandeh, J., Scheuer, T., Zheng, N., and Catterall, W. A. (2011). The crystal structure of a voltage-gated sodium channel. Nature 475, 353-358. doi: 10.1038/ nature 10238

Peng, K., Hu, J., Xiao, J., Dan, G., Yang, L., Ye, F., et al. (2018). Mitochondrial Atpsensitive potassium channel regulates mitochondrial dynamics to participate in neurodegeneration of Parkinson's disease. Biochim. Biophys. Acta 1864, 1086-1103. doi: 10.1016/j.bbadis.2018.01.013

Penzotti, J. L., Lipkind, G., Fozzard, H. A., Dudley, S. C. Jr. (2001). Specific neosaxitoxin interactions with the $\mathrm{Na}+$ channel outer vestibule determined by mutant cycle analysis. Biophys. J. 80, 698-706. doi: 10.1016/S0006-3495(01) 76049-3

Perez-Neut, M., Haar, L., Rao, V., Santha, S., Lansu, K., Rana, B., et al. (2016). Activation of herg3 channel stimulates autophagy and promotes cellular senescence in melanoma. Oncotarget 7, 21991-22004. doi: 10.18632/oncotarget. 7831

Perregaux, D., and Gabel, C. A. (1994). Interleukin-1 beta maturation and release in response to Atp and nigericin. Evidence that potassium depletion mediated by these agents is a necessary and common feature of their activity. J. Biol. Chem. $269,15195-15203$.

Peternelj, T.-T., and Coombes, J. S. (2011). Antioxidant supplementation during exercise training. Sports Med. 41, 1043-1069. doi: 10.2165/11594400000000000-00000

Petrilli, V., Papin, S., Dostert, C., Mayor, A., Martinon, F., and Tschopp, J. (2007). Activation of the Nalp3 inflammasome is triggered by low intracellular potassium concentration. Cell Death Differ. 14, 1583-1589. doi: 10.1038/sj.cdd. 4402195

Picca, A., Lezza, A. M. S., Leeuwenburgh, C., Pesce, V., Calvani, R., Landi, F., et al. (2017). Fueling inflamm-aging through mitochondrial dysfunction: mechanisms and molecular targets. Int. J. Mol. Sci. 18:E933. doi: 10.3390/ ijms 18050933

Pickrell, A. M., and Youle, R. J. (2015). The roles of Pink1, parkin, and mitochondrial fidelity in Parkinson's disease. Neuron 85, 257-273. doi: 10.1016/ j.neuron.2014.12.007

Pingle, S. C., Matta, J. A., and Ahern, G. P. (2007). Capsaicin receptor: Trpv1 a promiscuous Trp channel. Handb. Exp. Pharmacol. 179, 155-171. doi: 10.1007/ 978-3-540-34891-7_9

Pitozzi, V., Mocali, A., Laurenzana, A., Giannoni, E., Cifola, I., Battaglia, C., et al. (2013). Chronic resveratrol treatment ameliorates cell adhesion and mitigates the inflammatory phenotype in senescent human fibroblasts. J. Gerontol. A 68, 371-381. doi: 10.1093/gerona/gls183

Prince, M., Bryce, R., Albanese, E., Wimo, A., Ribeiro, W., and Ferri, C. P. (2013). The global prevalence of dementia: a systematic review and metaanalysis. Alzheimers Dement. 9:e2. doi: 10.1016/j.jalz.2012.11.007

Qi, H., Casalena, G., Shi, S., Yu, L., Ebefors, K., Sun, Y., et al. (2017). Glomerular endothelial mitochondrial dysfunction is essential and characteristic of diabetic kidney disease susceptibility. Diabetes 66, 763-778. doi: 10.2337/db16-0695

Qiang, W., Weiqiang, K., Qing, Z., Pengju, Z., and Yi, L. (2007). Aging impairs insulin-stimulated glucose uptake in rat skeletal muscle via suppressing Ampkalpha. Exp. Mol. Med. 39, 535-543. doi: 10.1038/emm.2007.59

Raeburn, C. D., Sheppard, F., Barsness, K. A., Arya, J., and Harken, A. H. (2002). Cytokines for surgeons. Am. J. Surg. 183, 268-273. doi: 10.1016/S0002-9610(02) 00781-X
Raffaello, A., Mammucari, C., Gherardi, G., and Rizzuto, R. (2016). Calcium at the center of cell signaling: interplay between endoplasmic reticulum, mitochondria, and lysosomes. Trends Biochem. Sci. 41, 1035-1049. doi: 10.1016/ j.tibs.2016.09.001

Ranki, H. J., Crawford, R. M., Budas, G. R., and Jovanovic, A. (2002). Ageing is associated with a decrease in the number of sarcolemmal Atp-sensitive $\mathrm{K}+$ channels in a gender-dependent manner. Mech. Ageing Dev. 123, 695-705. doi: 10.1016/S0047-6374(01)00415-8

Rao, V., Kaja, S., and Gentile, S. (2016). Ion Channels in Aging and Aging-Related Diseases, Molecular Mechanisms of the Aging Process and Rejuvenation. Available at: https://www.intechopen.com/books/molecular-mechanismsof-the- aging-process-and-rejuvenation/ion-channels-in-aging-and-agingrelated-diseases

Raturi, A., and Simmen, T. (2013). Where the endoplasmic reticulum and the mitochondrion tie the knot: the mitochondria-associated membrane (Mam). Biochim. Biophys. Acta 1833, 213-224. doi: 10.1016/j.bbamcr.2012.04.013

Rea, S. L., Ventura, N., and Johnson, T. E. (2007). Relationship between mitochondrial electron transport chain dysfunction, development, and life extension in Caenorhabditis elegans. PLoS Biol. 5:e259. doi: 10.1371/journal. pbio.0050259

Reale, M. (2014). Inflammation in Aging and Age-related Diseases. Journal of Gerontology \& Geriatr. Res. 3:e126.

Rebelo-Marques, A., De Sousa Lages, A., Andrade, R., Ribeiro, C. F., MotaPinto, A., Carrilho, F., et al. (2018). Aging hallmarks: the benefits of physical exercise. Front. Endocrinol. 9:258. doi: 10.3389/fendo.2018. 00258

Reddy, P. H., and Beal, M. F. (2008). Amyloid beta, mitochondrial dysfunction and synaptic damage: implications for cognitive decline in aging and Alzheimer's disease. Trends Mol. Med. 14, 45-53. doi: 10.1016/j.molmed.2007.12.002

Ren, J., Dominguez, L. J., Sowers, J. R., and Davidoff, A. J. (1999). Metformin but not glyburide prevents high glucose-induced abnormalities in relaxation and intracellular $\mathrm{Ca} 2+$ transients in adult rat ventricular myocytes. Diabetes 48 , 2059-2065. doi: 10.2337/diabetes.48.10.2059

Reznick, R. M., Zong, H., Li, J., Morino, K., Moore, I. K., Yu, H. J., et al. (2007). Aging-associated reductions in Amp-activated protein kinase activity and mitochondrial biogenesis. Cell Metab. 5, 151-156. doi: 10.1016/j.cmet.2007. 01.008

Rice, R. A., Berchtold, N. C., Cotman, C. W., and Green, K. N. (2014). Agerelated downregulation of the CaV3.1 T-type calcium channel as a mediator of amyloid beta production. Neurobiol. Aging 35, 1002-1011. doi: 10.1016/j. neurobiolaging.2013.10.090

Ridker, P. M., Libby, P., Macfadyen, J. G., Thuren, T., Ballantyne, C., Fonseca, F., et al. (2018). Modulation of the interleukin-6 signalling pathway and incidence rates of atherosclerotic events and all-cause mortality: analyses from the Canakinumab Anti-Inflammatory Thrombosis Outcomes Study (Cantos). Eur. Heart J. 39, 3499-3507. doi: 10.1093/eurheartj/ehy310

Rochat, H., Kharrat, R., Sabatier, J. M., Mansuelle, P., Crest, M., Martin-Eauclaire, M. F., et al. (1998). Maurotoxin, a four disulfide bridges scorpion toxin acting on K+ channels. Toxicon 36, 1609-1611. doi: 10.1016/S0041-0101(98)00153-6

Rodgers, J. T., Lerin, C., Haas, W., Gygi, S. P., Spiegelman, B. M., and Puigserver, P. (2005). Nutrient control of glucose homeostasis through a complex of Pgc1alpha and Sirt1. Nature 434, 113-118. doi: 10.1038/nature03354

Rodriguez-Cuenca, S., Monjo, M., Gianotti, M., Proenza, A. M., and Roca, P. (2007). Expression of mitochondrial biogenesis-signaling factors in brown adipocytes is influenced specifically by 17beta-estradiol, testosterone, and progesterone. Am. J. Physiol. Endocrinol. Metab. 292, E340-E346. doi: 10.1152/ ajpendo.00175.2006

Roscoe, A. K., Christensen, J. D., and Lynch, C. (2000). Isoflurane, but not halothane, induces protection of human myocardium via adenosine al receptors and adenosine triphosphate-sensitive potassium channels. Anesthesiology 92, 1692-1701. doi: 10.1097/00000542-200006000-00029

Rostovtseva, T. K., Gurnev, P. A., Protchenko, O., Hoogerheide, D. P., Yap, T. L., Philpott, C. C., et al. (2015). $\alpha$-synuclein shows high-affinity interaction with voltage-dependent anion channel suggesting mechanisms of mitochondrial regulation and toxicity in Parkinson disease. J. Biol. Chem. 290, 18467-18477. doi: $10.1074 /$ jbc.M115.641746

Rowan, M. J. M., Delcanto, G., Yu, J. J., Kamasawa, N., and Christie, J. M. (2016). Synapse-level determination of action potential duration by $\mathrm{K}+$ 
channel clustering in axons. Neuron 91, 370-383. doi: 10.1016/j.neuron.2016. 05.035

Saeed, Y., Temple, I. P., Borbas, Z., Atkinson, A., Yanni, J., Maczewski, M., et al. (2018). Structural and functional remodeling of the atrioventricular node with aging in rats: the role of hyperpolarization-activated cyclic nucleotide-gated and ryanodine 2 channels. Heart Rhythm 15, 752-760. doi: 10.1016/j.hrthm. 2017.12.027

Safo, P., Rosenbaum, T., Shcherbatko, A., Choi, D. Y., Han, E., Toledo-Aral, J. J., et al. (2000). Distinction among neuronal subtypes of voltage-activated sodium channels by mu-conotoxin Piiia. J. Neurosci. 20, 76-80. doi: 10.1523/ JNEUROSCI.20-01-00076.2000

Sala-Rabanal, M., Yurtsever, Z., Berry, K. N., and Brett, T. J. (2015). Novel roles for chloride channels. exchangers, and regulators in chronic inflammatory airway diseases. Med. Inflamm. 2015:497387. doi: 10.1155/2015/497387

Sanchez-Alonso, J. L., Schobesberger, S., Poulet, C. E., Bhogal, N., Chowdhury, R., and Gorelik, J. (2018). Function of L-type calcium channel microdomain in human myocytes from hearts with ischemic versus dilated cardiomyopathies. Biophys. J. 114:638a. doi: 10.1016/j.bpj.2017.11.3444

Santulli, G. R., and Marks, A. (2015). Essential roles of intracellular calcium release channels in muscle, brain, metabolism, and aging. Curr. Mol. Pharmacol. 8, 206-222. doi: 10.2174/1874467208666150507105105

Satrustegui, J., Villalba, M., Pereira, R., Bogonez, E., and Martinez-Serrano, A. (1996). Cytosolic and mitochondrial calcium in synaptosomes during aging. Life Sci. 59, 429-434. doi: 10.1016/0024-3205(96)00322-0

Scarpulla, R. C., Vega, R. B., and Kelly, D. P. (2012). Transcriptional integration of mitochondrial biogenesis. Trends Endocrinol. Metab. 23, 459-466. doi: 10.1016/ j.tem.2012.06.006

Schafer, M. J., White, T. A., Iijima, K., Haak, A. J., Ligresti, G., Atkinson, E. J., et al. (2017). Cellular senescence mediates fibrotic pulmonary disease. Nat. Commun. 8, 14532-14532. doi: $10.1038 /$ ncomms 14532

Schilling, T., and Eder, C. (2015). Microglial K+ channel expression in young adult and aged mice. Glia 63, 664-672. doi: 10.1002/glia.22776

Scholze, A., Plant, T. D., Dolphin, A. C., and Nurnberg, B. (2001). Functional expression and characterization of a voltage-gated CaV1.3 (alpha1D) calcium channel subunit from an insulin-secreting cell line. Mol. Endocrinol. 15, 1211-1221.

Schram, M. T., Euser, S. M., De Craen, A. J., Witteman, J. C., Frolich, M., Hofman, A., et al. (2007). Systemic markers of inflammation and cognitive decline in old age. J. Am. Geriatr. Soc. 55, 708-716. doi: 10.1111/j.1532-5415. 2007.01159.x

Scragg, J. L., Jones, R. D., Channer, K. S., Jones, T. H., and Peers, C. (2004). Testosterone is a potent inhibitor of L-type $\mathrm{Ca}(2+)$ channels. Biochem. Biophys. Res. Commun. 318, 503-506. doi: 10.1016/j.bbrc.2004.04.054

Seo, A. Y., Joseph, A. M., Dutta, D., Hwang, J. C., Aris, J. P., and Leeuwenburgh, C. (2010). New insights into the role of mitochondria in aging: mitochondrial dynamics and more. J. Cell Sci. 123, 2533-2542. doi: 10.1242/jcs. 070490

Shaftel, S. S., Griffin, W. S., and O'banion, M. K. (2008). The role of interleukin1 in neuroinflammation and Alzheimer disease: an evolving perspective. J. Neuroinflammation 5:7. doi: 10.1186/1742-2094-5-7

Shakkottai, V. G., Regaya, I., Wulff, H., Fajloun, Z., Tomita, H., Fathallah, M., et al. (2001). Design and characterization of a highly selective peptide inhibitor of the small conductance calcium-activated $\mathrm{K}+$ channel, SkCa2. J. Biol. Chem. 276, 43145-43151. doi: 10.1074/jbc.M106981200

Shaw, J. E., Sicree, R. A., and Zimmet, P. Z. (2010). Global estimates of the prevalence of diabetes for 2010 and 2030. Diabetes Res. Clin. Pract. 87, 4-14. doi: 10.1016/j.diabres.2009.10.007

Shimokata, H., and Ando, F. (2017). Long-term longitudinal epidemiological study of frailty and sarcopenia. Jpn. J. Phys. Fit. Sports Med. 66, 133-142. doi: 10.7600/ jspfsm.66.133

Shum, L. C., White, N. S., Nadtochiy, S. M., Bentley, K. L. D. M., Brookes, P. S., Jonason, J. H., et al. (2016). Cyclophilin D knock-out mice show enhanced resistance to osteoporosis and to metabolic changes observed in aging bone. PLoS One 11:e0155709. doi: 10.1371/journal.pone.0155709

Simkin, D., Hattori, S., Ybarra, N., Musial, T. F., Buss, E. W., Richter, H., et al. (2015). Aging-related hyperexcitability in Ca3 pyramidal neurons is mediated by enhanced A-Type K+ channel function and expression. J. Neurosci. 35, 13206-13218. doi: 10.1523/JNEUROSCI.0193-15.2015
Simms, Brett, A., and Zamponi, G. W. (2014). Neuronal voltage-gated calcium channels: structure, Function, and Dysfunction. Neuron 82, 24-45. doi: 10. 1016/j.neuron.2014.03.016

Sklirou, E., and Lichter-Konecki, U. (2018). Inborn errors of metabolism with cognitive impairment: metabolism defects of phenylalanine, homocysteine and methionine, purine and pyrimidine, and creatine. Pediatr. Clin. North Am. 65, 267-277. doi: 10.1016/j.pcl.2017.11.009

Smith, R. A. J., Porteous, C. M., Coulter, C. V., and Murphy, M. P. (1999). Selective targeting of an antioxidant to mitochondria. Eur. J. Biochem. 263, 709-716. doi: 10.1046/j.1432-1327.1999.00543.x

Snyder, H. M., Corriveau, R. A., Craft, S., Faber, J. E., Greenberg, S. M., Knopman, D., et al. (2015). Vascular contributions to cognitive impairment and dementia including Alzheimer's disease. Alzheimers Dement. 11, 710-717. doi: 10.1016/j.jalz.2014.10.008

Son, J. M., Sarsour, E. H., Kakkerla Balaraju, A., Fussell, J., Kalen, A. L., Wagner, B. A., et al. (2017). Mitofusin 1 and optic atrophy 1 shift metabolism to mitochondrial respiration during aging. Aging Cell 16, 1136-1145. doi: 10.1111/ acel.12649

Song, L., Mcmackin, M., Nguyen, A., and Cortopassi, G. (2017). Parkin deficiency accelerates consequences of mitochondrial DNA deletions and Parkinsonism. Neurobiol. Dis. 100, 30-38. doi: 10.1016/j.nbd.2016.12.024

Srivastava, S. (2017). The mitochondrial basis of aging and age-related disorders. Genes 8:398. doi: 10.3390/genes8120398

Stankowski, J. N., and Gupta, R. (2011). Therapeutic targets for neuroprotection in acute ischemic stroke: lost in translation? Antioxid. Redox Signal. 14, 18411851. doi: 10.1089 /ars.2010.3292

Starr, M. E., and Saito, H. (2014). Sepsis in old age: review of human and animal studies. Aging Dis. 5, 126-136.

Steenman, M., and Lande, G. (2017). Cardiac aging and heart disease in humans. Biophys. Rev. 9, 131-137. doi: 10.1007/s12551-017-0255-9

Stenvinkel, P., Ketteler, M., Johnson, R. J., Lindholm, B., Pecoits-Filho, R., Riella, M., et al. (2005). Il-10, Il-6, and Tnf- $\alpha$ : central factors in the altered cytokine network of uremia-The good, the bad, and the ugly. Kidney Int. 67, 1216-1233. doi: 10.1111/j.1523-1755.2005.00200.x

Steven, S., Hollingsworth, K. G., Al-Mrabeh, A., Avery, L., Aribisala, B., Caslake, M., et al. (2016). Very low-calorie diet and 6 months of weight stability in type 2 diabetes: pathophysiological changes in responders and nonresponders. Diabetes Care 39, 808-815. doi: 10.2337/dc15-1942

Strobaek, D., Hougaard, C., Johansen, T. H., Sorensen, U. S., Nielsen, E. O., Nielsen, K. S., et al. (2006). Inhibitory gating modulation of small conductance $\mathrm{Ca} 2+-$ activated $\mathrm{K}+$ channels by the synthetic compound (R)-N-(benzimidazol-2yl)-1,2,3,4-tetrahydro-1-naphtylamine (Ns8593) reduces afterhyperpolarizing current in hippocampal Cal neurons. Mol. Pharmacol. 70, 1771-1782. doi: 10.1124/mol.106.027110

Subramanian, N., Natarajan, K., Clatworthy, M. R., Wang, Z., and Germain, R. N. (2013). The adaptor Mavs promotes Nlrp3 mitochondrial localization and inflammasome activation. Cell 153, 348-361. doi: 10.1016/j.cell.2013. 02.054

Swart, T., and Hurley, M. J. (2016). Calcium channel antagonists as diseasemodifying therapy for parkinson's disease: therapeutic rationale and current status. Cns Drugs 30, 1127-1135. doi: 10.1007/s40263-016-0393-9

Tang, T., Lang, X., Xu, C., Wang, X., Gong, T., Yang, Y., et al. (2017). Clicsdependent chloride efflux is an essential and proximal upstream event for Nlrp3 inflammasome activation. Nat. Commun. 8:202. doi: 10.1038/s41467017-00227-x

Testai, L., Rapposelli, S., Martelli, A., Breschi, M. C., and Calderone, V. (2015). Mitochondrial potassium channels as pharmacological target for cardioprotective drugs. Med. Res. Rev. 35, 520-553. doi: 10.1002/med.21332

Toro, L., Marijic, J., Nishimaru, K., Tanaka, Y., Song, M., and Stefani, E. (2002). Aging, ion channel expression, and vascular function. Vascul. Pharmacol. 38, 73-80. doi: 10.1016/S0306-3623(02)00128-3

Towbin, J. A., and Jefferies, J. L. (2017). Cardiomyopathies due to left ventricular noncompaction, mitochondrial and storage diseases, and inborn errors of metabolism. Circ. Res. 121, 838-854. doi: 10.1161/CIRCRESAHA.117.310987

Trimmer, J. S., Cooperman, S. S., Tomiko, S. A., Zhou, J. Y., Crean, S. M., Boyle, M. B., et al. (1989). Primary structure and functional expression of a mammalian skeletal muscle sodium channel. Neuron 3, 33-49. doi: 10.1016/ 0896-6273(89)90113-X 
Truong, A. H., Murugesan, S., Youssef, K. D., and Makino, A. (2016). "Mitochondrial Ion channels in metabolic disease," in Vascular Ion Channels in Physiology and Disease, eds P. I. Levitan and M. D. P. A. Dopico (Cham: Springer International Publishing).

Vakifahmetoglu-Norberg, H., Ouchida, A. T., and Norberg, E. (2017). The role of mitochondria in metabolism and cell death. Biochem. Biophys. Res. Commun. 482, 426-431. doi: 10.1016/j.bbrc.2016.11.088

Van Exel, E., Gussekloo, J., De Craen, A., Bootsma-Van Der, Wiel, A., Frölich, M., et al. (2002). Inflammation and stroke: the Leiden 85-plus study. Stroke 33, 1135-1138. doi: 10.1161/01.STR.0000014206.05597.9E

Van Raamsdonk, J. M., and Hekimi, S. (2009). Deletion of the mitochondrial superoxide dismutase sod-2 extends lifespan in Caenorhabditis elegans. PLoS Genet. 5:e1000361. doi: 10.1371/journal.pgen.1000361

Van Raamsdonk, J. M., and Hekimi, S. (2012). Superoxide dismutase is dispensable for normal animal lifespan. Proc. Natl. Acad. Sci. U.S.A. 109, 5785-5790. doi: $10.1073 /$ pnas. 1116158109

Vernon, H. J. (2015). Inborn errors of metabolism: advances in diagnosis and therapy. JAMA Pediatr. 169, 778-782. doi: 10.1001/jamapediatrics.2015.0754

Viollet, B., Guigas, B., Garcia, N. S., Leclerc, J., Foretz, M., and Andreelli, F. (2012). Cellular and molecular mechanisms of metformin: an overview. Clin. Sci. 122, 253-270. doi: 10.1042/CS20110386

Visser, M., Pahor, M., Taaffe, D. R., Goodpaster, B. H., Simonsick, E. M., Newman, A. B., et al. (2002). Relationship of interleukin-6 and tumor necrosis factor$\alpha$ with muscle mass and muscle strength in elderly men and women the health Abc study. J. Gerontol A 57, M326-M332. doi: 10.1093/gerona/57.5. M326

Vos, T., Abajobir, A. A., Abate, K. H., Abbafati, C., Abbas, K. M., AbdAllah, F., et al. (2017). Global, regional, and national incidence, prevalence, and years lived with disability for 328 diseases and injuries for 195 countries, 1990\&\#x2013;2016: a systematic analysis for the Global Burden of Disease Study 2016. Lancet 390, 1211-1259. doi: 10.1016/S0140-6736(17) 32154-2

Wai, T., and Langer, T. (2016). Mitochondrial dynamics and metabolic regulation. Trends Endocrinol. Metab. 27, 105-117. doi: 10.1016/j.tem.2015.12.001

Wang, H., Shi, H., Zhang, L., Pourrier, M., Yang, B., Nattel, S., et al. (2000). Nicotine is a potent blocker of the cardiac A-type $\mathrm{K}(+)$ channels. Effects on cloned Kv4.3 channels and native transient outward current. Circulation 102, 1165-1171. doi: 10.1161/01.CIR.102.10.1165

Wang, T., Tsui, B., Kreisberg, J. F., Robertson, N. A., Gross, A. M., Yu, M. K., et al. (2017). Epigenetic aging signatures in mice livers are slowed by dwarfism, calorie restriction and rapamycin treatment. Genome Biol. 18:57. doi: 10.1186/ s13059-017-1186-2

Warnier, M., Flaman, J.-M., Chouabe, C., Wiel, C., Gras, B., Griveau, A., et al. (2018). The Scn9A channel and plasma membrane depolarization promote cellular senescence through Rb pathway. Aging Cell 17:e12736. doi: 10.1111/ acel.12736

Watanabe, S., Kawamoto, S., Ohtani, N., and Hara, E. (2017). Impact of senescenceassociated secretory phenotype and its potential as a therapeutic target for senescence-associated diseases. Cancer Sci. 108, 563-569. doi: 10.1111/cas. 13184

Weaver, J. D., Huang, M. H., Albert, M., Harris, T., Rowe, J. W., and Seeman, T. E. (2002). Interleukin-6 and risk of cognitive decline: Mac Arthur studies of successful aging. Neurology 59, 371-378. doi: 10.1212/WNL.59. 3.371

Wei, M., Brandhorst, S., Shelehchi, M., Mirzaei, H., Cheng, C. W., Budniak, J., et al. (2017). Fasting-mimicking diet and markers/risk factors for aging, diabetes, cancer, and cardiovascular disease. Sci. Transl. Med. 9:eaai8700.

Wei Enoch, P., Kontos Hermes, A., and Beckman Joseph, S. (1998). Antioxidants Inhibit Atp-sensitive potassium channels in cerebral arterioles. Stroke 29, 817-823. doi: 10.1161/01.STR.29.4.817

West, R., and Jones, D. (2013). Cardiac rehabilitation and mortality reduction after myocardial infarction: the emperor's new clothes? Evid. Against Cardiac. Rehabil. 99, 911-913. doi: 10.1136/heartjnl-2013-303705
Westendorp, R. G. (2004). Are we becoming less disposable? EMBO Rep. 5, 2-6. Wiel, C., Lallet-Daher, H., Gitenay, D., Gras, B., Le Calve, B., Augert, A., et al. (2014). Endoplasmic reticulum calcium release through Itpr2 channels leads to mitochondrial calcium accumulation and senescence. Nat. Commun. 5:3792. doi: $10.1038 /$ ncomms4792

Wierman, M. B., Maqani, N., Strickler, E., Li, M., and Smith, J. S. (2017). Caloric restriction extends yeast chronological life span by optimizing the Snf1 (Ampk) signaling pathway. Mol. Cell. Biol. 37, e562-e516. doi: 10.1128/MCB.00562-16

Wiley, C. D., and Campisi, J. (2016). From ancient pathways to aging cellsconnecting metabolism and cellular senescence. Cell Metab. 23, 1013-1021. doi: 10.1016/j.cmet.2016.05.010

Wilson, C. J., Finch, C. E., and Cohen, H. J. (2002). Cytokines and cognitionthe case for a head-to-toe inflammatory paradigm. J. Am. Geriatr. Soc. 50, 2041-2056. doi: 10.1046/j.1532-5415.2002.50619.x

World Health Organization (2015). World Report on Ageing and Health. Geneva: World Health Organization.

Yang, K.-C., and Nerbonne, J. M. (2016). Mechanisms contributing to myocardial potassium channel diversity, regulation and remodeling. Trends Cardiovasc. Med. 26, 209-218. doi: 10.1016/j.tcm.2015.07.002

Yang, Y., and Lee, L. C. (2009). Dynamics and heterogeneity in the process of human frailty and aging: evidence from the Us older adult population. J. Gerontol. B 65, 246-255.

Yee, C., Yang, W., and Hekimi, S. (2014). The intrinsic apoptosis pathway mediates the pro-longevity response to mitochondrial Ros in C. elegans. Cell 157, 897-909. doi: 10.1016/j.cell.2014.02.055

Yu, X.-W., Hu, Z.-L., Ni, M., Fang, P., Zhang, P.-W., Shu, Q., et al. (2015). Acidsensing ion channels promote the inflammation and migration of cultured rat microglia. Glia 63, 483-496. doi: 10.1002/glia.22766

Yun, A. J., and Lee, P. Y. (2004). Maldaptation of the link between inflammation and bone turnover may be a key determinant of osteoporosis. Med. Hypotheses 63, 532-537. doi: 10.1016/S0306-9877(03)00326-8

Yun, J., and Finkel, T. (2014). Mitohormesis. Cell Metab. 19, 757-766. doi: 10.1016/ j.cmet.2014.01.011

Zampieri, S., Mammucari, C., Romanello, V., Barberi, L., Pietrangelo, L., Fusella, A., et al. (2016). Physical exercise in aging human skeletal muscle increases mitochondrial calcium uniporter expression levels and affects mitochondria dynamics. Physiol. Rep. 4:e13005. doi: 10.14814/phy2. 13005

Zanon, A., Kalvakuri, S., Rakovic, A., Foco, L., Guida, M., Schwienbacher, C., et al. (2017). Slp-2 interacts with Parkin in mitochondria and prevents mitochondrial dysfunction in Parkin-deficient human ipsc-derived neurons and Drosophila. Hum. Mol. Genet. 26, 2412-2425. doi: 10.1093/hmg/ ddx132

Zhang, Y., Song, C., Zhang, J., Bo, H., and Ji, L. L. (2018). Exercise training induced anti-inflammatory il-6 in aged skeletal muscle: role of mitochondrial homeostasis. Med. Sci. Sports Exercise 50:198. doi: 10.1249/01.mss.0000535737. 45954.59

Zhao, D., Sun, Y., Tan, Y., Zhang, Z., Hou, Z., Gao, C., et al. (2018). Short-duration swimming exercise after myocardial infarction attenuates cardiac dysfunction and regulates mitochondrial quality control in aged mice. Oxid. Med. Cell. Longev. 2018:4079041. doi: 10.1155/2018/4079041

Conflict of Interest Statement: The authors declare that the research was conducted in the absence of any commercial or financial relationships that could be construed as a potential conflict of interest.

Copyright (C) 2019 Strickland, Yacoubi-Loueslati, Bouhaouala-Zahar, Pender and Larbi. This is an open-access article distributed under the terms of the Creative Commons Attribution License (CC BY). The use, distribution or reproduction in other forums is permitted, provided the original author(s) and the copyright owner(s) are credited and that the original publication in this journal is cited, in accordance with accepted academic practice. No use, distribution or reproduction is permitted which does not comply with these terms. 